UNIVERSIDADE DE SÃO PAULO

FACULDADE DE MEDICINA DE RIBEIRÃO PRETO

DEPARTAMENTO DE FARMACOLOGIA

Vinicius A. H. Sato

\title{
Participação da serotonina no efeito tipo- antidepressivo induzido pela inibição da nNOS no hipocampo de ratos
}


VINICIUS A. H. SATO

\section{Participação da serotonina no efeito tipo- antidepressivo induzido pela inibição da nNOS no hipocampo de ratos}

Dissertação apresentada ao Programa de Pós-Graduação em Farmacologia da Faculdade de Medicina de Ribeirão Preto - Universidade de São Paulo, para a obtenção do título de Mestre em Ciências.

Área de Concentração: Farmacologia Orientador: Profa. Dra. Sâmia Regiane Lourenço Joca

Ribeirão Preto - SP 
AUTORIZO A DIVULGAÇÃO TOTAL OU PARCIAL DESTE TRABALHO, POR QUALQUER MEIO CONVENCIONAL OU ELETRÔNICO, PARA FINS DE ESTUDO E PESQUISA, DESDE QUE CITADA A FONTE.

FICHA CATALOGRÁFICA

Sato, Vinicius Antonio Hiroaki

Participação da serotonina no efeito tipo-antidepressivo induzido pela inibição da nNOS no hipocampo de ratos. Ribeirão Preto, 2011.

73 p. : il. ; $30 \mathrm{~cm}$

Dissertação de Mestrado, apresentada à Faculdade de Medicina de Ribeirão Preto/USP. Área de concentração: Farmacologia.

Orientadora: Lourenço Joca, Sâmia Regiane.

1. Depressão. 2. Óxido nítrico. 3. Serotonina.

4. Teste do nado forçado. 5. nNOS. 
FOLHA DE APROVAÇÃO

Vinicius Antonio Hiroaki Sato

\title{
Participação da serotonina no efeito tipo- antidepressivo induzido pela inibição da nNOS no hipocampo de ratos
}

\author{
Dissertação apresentada ao Programa de \\ Pós-Graduação em Farmacologia da Faculdade de \\ Medicina de Ribeirão Preto - Universidade de São \\ Paulo, como requisito parcial para a obtenção do \\ título de Mestre em Ciências.
}

Área de Concentração: Farmacologia

Aprovado em: 07/07/2011

Banca Examinadora:

Profa. Dra. Sâmia Regiane Lourenço Joca.

Instituição: FCFRP-USP.

Assinatura:

Profa. Dra. Rúbia Maria Monteiro Weffort de Oliveira.

Instituição: UEM - PR.

Assinatura:

Prof. Dr. Hélio Zangrossi Jr.

Instituição: FMRP-USP.

Assinatura: 
Por que ainda há pessoas que querem e insistem em acreditar na humanidade. 
Para Sirley, Antonio e Ana Luisa. 


\section{AGRADECIMENTOS}

À Prof ${ }^{\mathrm{a}}$. Dr ${ }^{\mathrm{a}}$. Sâmia Regiane Lourenço Joca, por ter me acolhido como orientado e como amigo. Pelo exemplo de pessoa, amizade, ética, profissional e humana, e pela confiança em mim depositada;

À Ana Luisa, que com muito amor me ajudou tanto nesses últimos dois anos. Por sua paciência, companheirismo, compreensão e principalmente por todo o amor e confiança, muito obrigado;

À minha família, pelo apoio constante e incondicional, mesmo com a distância;

A todos os meus amigos, por tudo o que representam e significam para mim;

Às professoras Dr ${ }^{\mathrm{a}}$. Claudete Faiad Name e Dr ${ }^{\mathrm{a}}$. Sílvia Ponzoni pelas lições de vida, ciência e amizade;

Aos professores Dr. Francisco Guimarães, Dr. Hélio Zangrossi Jr e Dr. Leonardo Resstel Barbosa Moraes, pelas conversas construtivas e aos demais professores do Programa de Pós Graduação em Farmacologia por todos os exemplos passados a mim sobre pesquisa e docência;

Aos professores Dra Rúbia M. W. de Oliveria e Dr. Hélio Zangrossi Jr, por terem aceitado prontamente ao convite de compor a banca, mesmo com prazos apertados e pelos construtivos conselhos que com certeza ajudaram a melhorar este trabalho;

Aos amigos Laena e Vitor pelo companheirismo, apoio e inestimável amizade;

Às amigas Eva e Luana por terem me acolhido pra dentro de suas vidas e terem constituído minha família em Ribeirão Preto;

Aos amigos e companheiros de bancada (Amanda, Ariandra, Carol, Cassiano, Deidiane, Evelyn, Karina, Laura, Mateus, Michelle, Michelly, Murilo, Rafaela) pela amizade, parceria, risadas e acima de tudo pelo espírito de grupo.

A José Waldik Ramón por todo o auxílio e principalmente pela amizade e conversas jogadas fora; 
A Zé Carlos, pela experiência transmitida, exemplo de profissional e amizade;

À Flávia Fiacadori Salata pela amizade e pelo indispensável apoio técnico;

Aos secretários Fátima Helena Petean, Marlene Rodrigues da Silva, e Sônia Maria Stefanelli pela inestimável ajuda e amizade construída;

Aos funcionários da Farmacologia da FCFRP, Miriam, Juliana, Mayara, Marcela e D. Nina, pela amizade e agradável convívio;

Aos amigos e companheiros da pós-graduação por cada momento de aprendizado e convívio juntos, mas principalmente pelos momentos de diversão;

Às agências de fomento, CAPES, CNPq e FAPESP, pelo auxílio financeiro;

Obrigado por tudo! 


\section{RESUMO}

SATO, V.A.H. Participação da serotonina no efeito tipo-antidepressivo induzido pela inibição da nNOS no hipocampo de ratos. 2011. 73f. Disertação (Mestrado) - Faculdade de Medicina de Ribeirão Preto, Universidade de São Paulo, Ribeirão Preto, 2011.

Introdução: $\mathrm{O}$ óxido nítrico (NO) é considerado um importante neuromodulador que está envolvido com a neurobiologia da adaptação ao estresse e da depressão. A administração sistêmica ou intra-hipocampal de inibidores da NO sintase neuronial (nNOS) induz efeitos do tipo antidepressivo em modelos animais. Evidências recentes indicam que os efeitos sistêmicos dos inibidores da nNOS são dependentes dos níveis de serotonina no encéfalo. $\mathrm{O}$ sistema serotoninérgico do hipocampo dorsal, por ativação dos receptores serotoninérgicos do tipo $1 \mathrm{~A}\left(5 \mathrm{HT}_{1 \mathrm{~A}}\right)$, facilita a adaptação ao estresse e contribui para os efeitos comportamentais de drogas antidepressivas. Portanto, o objetivo do presente estudo foi testar a hipótese de que o efeito do tipo antidepressivo induzido pela administração hipocampal de inibidores da nNOS seria mediado pela facilitação da neurotransmissão serotoninérgica local e subseqüente ativação de receptores $5 \mathrm{HT}_{1 \mathrm{~A}}$. Métodos: Após cirurgia estereotáxica, ratos Wistar com cânulas-guia direcionadas ao hipocampo dorsal foram submetidos a sessão de pré-teste (15 minutos de nado) e receberam administrações locais das drogas: $n^{\omega}$-propil-L-arginina (NPA, inibidor seletivo da nNOS: 0,00001 - $1 \mathrm{nmol} / 0,5 \mu \mathrm{L}$ ), fluoxetina (inibidor seletivo da recaptação de serotonina - ISRS; 1, 3 e $10 \mathrm{nmol} / 0,5 \mu \mathrm{L}$ ), WAY100635 (antagonista seletivo para receptores $\left.5 \mathrm{HT}_{1 \mathrm{~A}} ; 1,3 \mathrm{e} 10 \mathrm{nmol} / 0,5 \mu \mathrm{L}\right)$ ou veículo $(0,5 \mu \mathrm{L})$. Vinte e quatro horas depois, o tempo de imobilidade foi registrado em uma sessão de 5 minutos de nado. Todos os protocolos foram aprovados por um comitê de ética local (Proc. No 08.1.1133.53.4). Resultados: A administração intra hipocampal de NPA ou fluoxetina reduziu significativamente o tempo de imobilidade em animais submetidos ao teste do nado forçado, um efeito tipo antidepressivo. A administração de WAY100635 não induziu efeito por si, mas foi capaz de bloquear os efeitos induzidos por fluoxetina ou NPA. Conclusões: A inibição da nNOS, pelo NPA, ou a inibição da recaptação de serotonina, pela fluoxetina, no DH induziu efeito do tipo antidepressivo de similar magnitude. $O$ fato de que o pré-tratamento com WAY100635 foi capaz de bloquear os efeitos induzidos por NPA e fluoxetina sugere que ambos os efeitos são mediados por facilitação da neurotransmissão serotoninérgica local e subseqüente ativação de receptores $5 \mathrm{HT}_{1 \mathrm{~A}}$. Assim, esses resultados sugerem que níveis aumentados de NO no DH poderiam levar a um déficit na neurotransmissão serotoninérgica local e, portanto, predispor ao desenvolvimento das conseqüências comportamentais do estresse. 


\begin{abstract}
SATO, V.A.H. Serotonin participation in the antidepressant-like effect induced by hippocampal nNOS inhibition. 2011. 731. Thesis (Masters) - Faculdade de Medicina de Ribeirão Preto, Universidade de São Paulo, Ribeirão Preto, 2011.

Introduction: Nitric oxide (NO) has been suggested to play an important role in the neurobiology of stress adaptation and depression. The systemic or hippocampal administration of neuronal NO synthase (nNOS) inhibitors induces antidepressant-like effects in animal models. Recent evidence indicates that the systemic effects of nNOS inhibitors are dependent on serotonin levels in the brain. The serotonergic system of the dorsal hippocampus, through the activation of serotonin $1 \mathrm{~A}\left(5-\mathrm{HT}_{1 \mathrm{~A}}\right)$ receptors, is proposed to mediate stress adaptation and the behavioral effects of antidepressant drugs. Therefore, the aim of the present study was to test the hypothesis that the antidepressant-like effects induced by nNOS inhibition into the hippocampus would be mediated by a facilitation of the local serotonergic neurotransmission and subsequent 5- $\mathrm{HT}_{1 \mathrm{~A}}$ receptors activation. Methods: Male Wistar rats with guide-cannulae aimed at the dorsal hippocampus were submitted to the pretest session (15 minutes of swimming) and received local administrations of the drugs: npropyl-L-arginine (NPA, selective nNOS inhibitor; $0.00001-1 \mathrm{nmol} / 0.5 \mu \mathrm{L}$ ), fluoxetine (selective serotonin recaptation inhibitor; 1,3 and $10 \mathrm{nmol} / 0.5 \mu \mathrm{L}$ ), WAY100635 (selective $5-\mathrm{HT}_{1 \mathrm{~A}}$ receptors antagonist: 1,3 and $\left.10 \mathrm{nmol} / 0.5 \mu \mathrm{L}\right)$ or vehicle $(0.5 \mu \mathrm{L})$. One day later, the immobility time was registered at a 5 minutes swimming test session. All protocols were approved by a local ethical committee (Proc. N. 08.1.1133.53.4.). Results: The intrahippocampal administration of NPA or fluoxetine reduced the immobility time in animals submitted to the forced swimming test, an antidepressant-like effect in this model. WAY100635 did not induce any effect per se, but it was able to block the effects induced by fluoxetine or NPA. Conclusions: Inhibition of nNOS, by NPA, or inhibition of serotonin reuptake, by fluoxetine, in the dorsal hippocampus induced antidepressant-like effects of similar magnitude. The fact that pretreatment with WAY100635 was able to block NPA- and fluoxetine-induced effects indicates that both effects are mediated by a facilitation of the local serotonergic neurotransmission and subsequent activation of $5-\mathrm{HT}_{1 \mathrm{~A}}$ receptors. Therefore, these results suggest that increased NO levels in the dorsal hippocampus could impair local serotonergic neurotransmission and, thus, predisposes to the development of stress-induced behavioral consequences, such as depressive-like behaviors.
\end{abstract}




\section{LISTA DE FIGURAS}

Figura 01 - Sítios representativos da administração de drogas no hipocampo dorsal de ratos

Figura 02 - Administração intra-hipocampal de NPA induz efeitos do tipo antidepressivo em ratos submetidos ao teste do nado forçado

Figura 03 - Administração intra-hipocampal de fluoxetina induz efeitos do tipo antidepressivo em ratos submetidos ao teste do nado forçado ....

Figura 04 - Administração intra-hipocampal de WAY100635 não altera o comportamento de ratos submetidos ao teste do nado forçado

Figura 05 - Pré-administração de WAY100635 bloqueia os efeitos induzidos pela fluoxetina em ratos submetidos ao teste do nado forçado

Figura 06 - Pré-administração de WAY100635 bloqueia os efeitos do NPA em ratos submetidos ao teste do nado forçado. 


\section{LISTA DE ABREVIATURAS}

$\mathbf{5 H T}_{\mathbf{1 A}}-$ Receptor serotoninérgico do tipo 1A.

5HTT - Proteína recaptadora de serotonina ou Recaptador de serotonina.

8-OH-DPAT - 8-Hidroxi- $N, N$-dipropil-2aminotetralina.

ACPC - Ácido 1-aminociclopropanocarboxílico.

AP-7 - Ácido 2-amino-7-fosfonoheptanóico.

BDNF - Fator neurotrófico derivado do cérebro (brain derived neurotrophic factor).

cAMP - Adenosina monofosfato cíclica (cyclic adenosine monophosphate)

CGP 37849 - Ácido (E,2R)-2-amino-4-methil-5fosfonopent-3-enóico.

CGP 39551 - Ácido etil éster (E)-( \pm )-2-Amino-4methil-5-fosfono-3-pentenóico.

CID-10 - Classificação internacional estatística das doenças e problemas de saúde relacionados $10^{\mathrm{a}}$ versão.

CREB - Proteína ligante aos elementos responsivos ao cAMP (cAMP response element binding protein).

CUMS - Estresse crônico variado imprevisível (Chronic Unpredictable Mild Stress).

DRN - Núcleo Dorsal da Rafe.

Eixo HPA - Eixo hipotálamo - pituitária - adrenal.

eNOS - Isoforma endotelial da óxido nítrico sintase.

FSL - Linhagem sensível de Flanders (Flanders Sensistive Line).

iNOS - isoforma induzível da óxido nítrico sintase.

Ki - Constante de inibição.

MK-801 - Dizolcipina.

NMDA - N-metil-D-aspartato.
nNOS - Isoforma neuronial da óxido nítrico sintase.

NO - Óxido nítrico.

NOS - Óxido nítrico sintase.

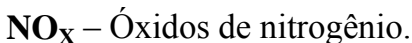

NPA - $\mathrm{N}^{\omega}$-propil-L-arginina.

PCPA - p-clorofenilalanina.

PSA-NCAM - Molécula de adesão de células neurais polisialilada (polysialylated-neural cell adhesion molecule).

sGC - Guanilato ciclase solúvel (soluble guanilate cyclase)

SNC - Sistema Nervoso Central.

ISRS - Inibidor Seletivo da Recaptação de Serotonina (Serotonin Selective Recaptation Inhibitor).

TST - Teste da Suspensão pela cauda (Tail Suspension Test).

WAY100635 - $N$-[2-[4-(2-metoxifenil)-1piperazinil]etil]- $N-(2-$ piridil)ciclohexanecarboxamida. 


\section{SUMÁRIO}

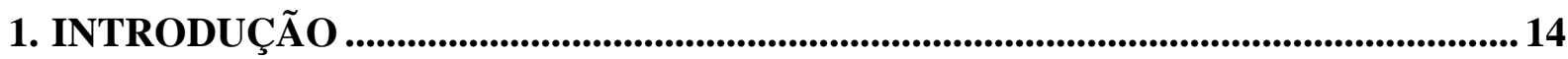

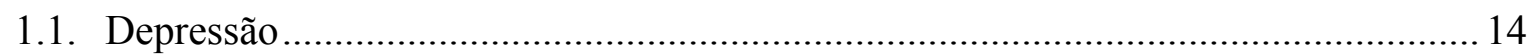

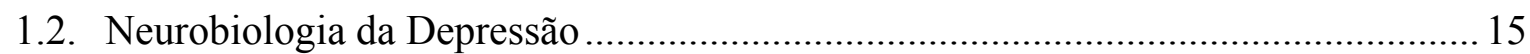

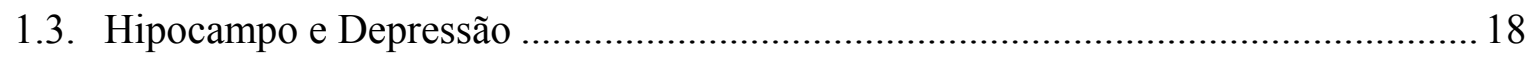

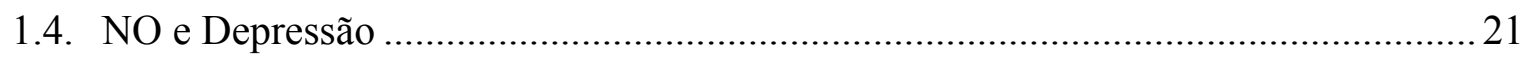

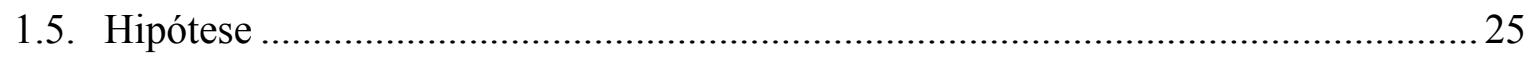

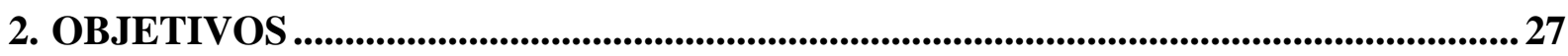

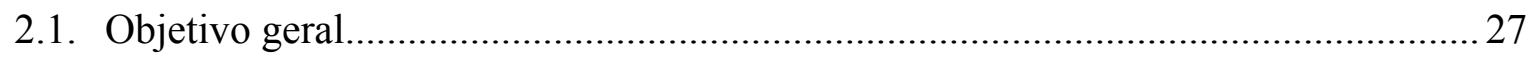

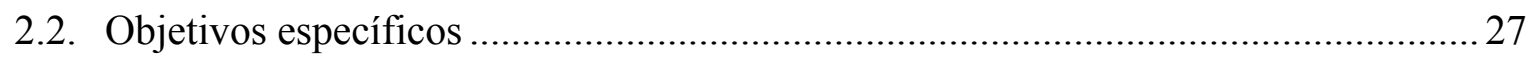

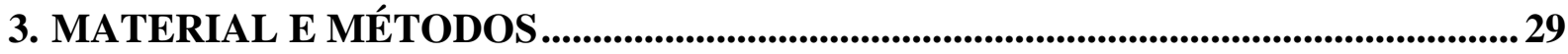

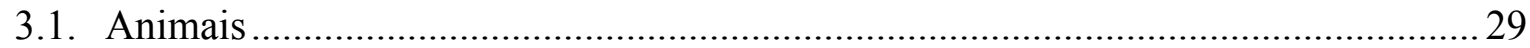

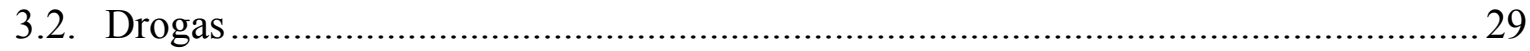

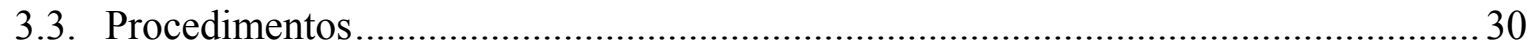

3.3.1. Cirurgia estereotáxica e administração intracerebral de drogas ........................ 30

3.3.2. Análise Histológica dos sítios de administração de drogas ............................... 31

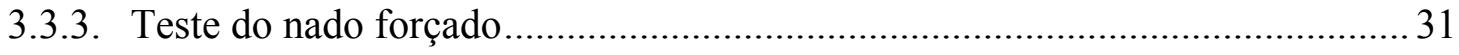

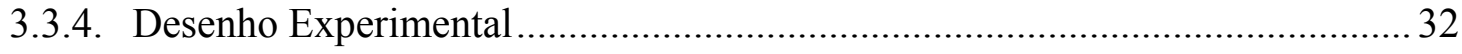

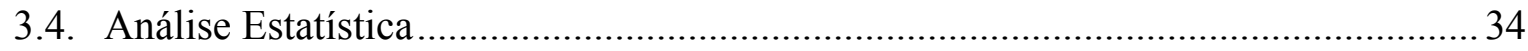

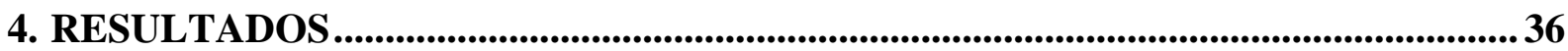

4.1. Efeitos da administração intra-hipocampo dorsal de NPA em ratos submetidos ao

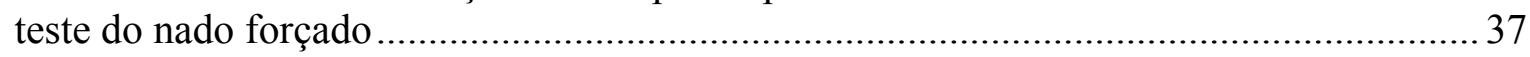

4.2. Efeitos da administração intra-hipocampo dorsal de fluoxetina em ratos

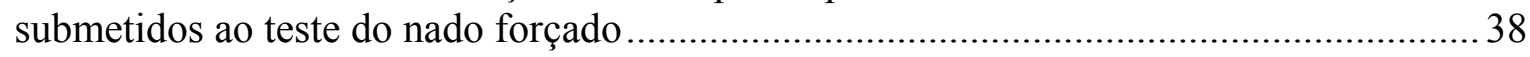

4.3. Efeitos da administração intra-hipocampo dorsal de WAY100635 em ratos

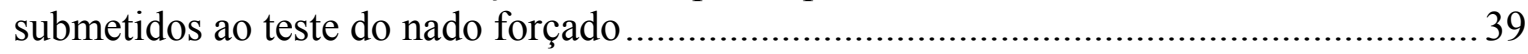

4.4. Efeitos da pré-administração de WAY100635 nos efeitos comportamentais

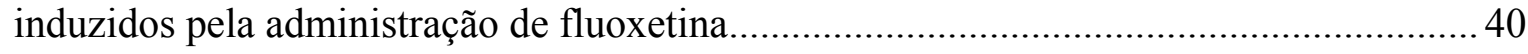

4.5. Efeitos da pré-administração de WAY100635 nos efeitos comportamentais

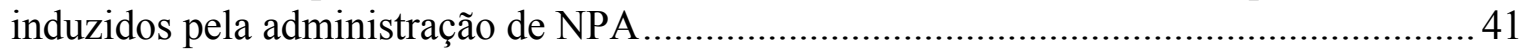

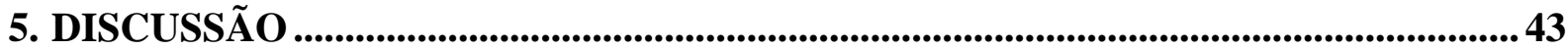

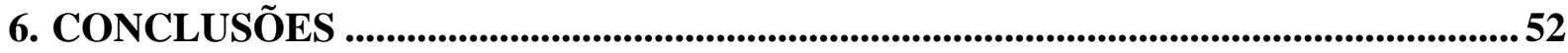

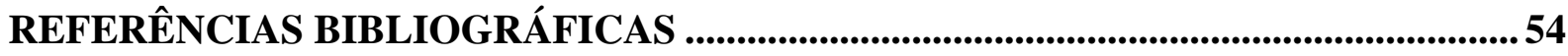


INTRODUÇÃO 


\section{INTRODUÇÃO}

\subsection{Depressão}

Segundo a Classificação Internacional das Doenças, décima versão (CID-10), organizada pela Organização Mundial da Saúde, transtornos afetivos são os transtornos onde o distúrbio principal ou fundamental seria uma mudança no humor ou no estado afetivo para depressão (com ou sem associação a ansiedade) ou para elação. Esses transtornos passam a interferir significativamente no desempenho das atividades cotidianas do indivíduo e a maioria dos outros sintomas é secundária ao - ou podem ser entendidos no - contexto da alteração do humor e na atividade alterada. Dentre esses transtornos, se incluem os episódios maníacos, o transtorno afetivo bipolar e os transtornos depressivos, onde temos os episódios depressivos, o transtorno depressivo recorrente e outros transtornos ditos persistentes, como a ciclotimia e a distimia (Organização Mundial da Saúde, 2007).

Nos episódios típicos de depressão, o indivíduo sofre de humor deprimido, redução de energia e diminuição das atividades normais. A capacidade de se divertir, interesse e concentração estão reduzidos e cansaço acentuado após mínimos esforços é comum. Sono e apetite também estão desregulados para mais ou para menos. Auto-estima e autoconfiança são quase sempre reduzidas e, mesmo na forma mais leve, pensamentos de culpa e inutilidade são freqüentemente presentes. O humor deprimido varia pouco ao longo dos dias, sendo irresponsivo às circunstâncias normais de flutuação do humor e pode ser acompanhado por sintomas como falta de interesse e falta de sentimentos prazerosos, despertar muito mais cedo do que o usual, com depressão mais acentuada pela manhã, retardo psicomotor, agitação, e perda de libido. Dependendo do número e severidade de sintomas, um episódio depressivo pode ser classificado em leve, moderado ou severo. Episódios repetidos de depressão como os descritos caracteriza o que é chamado de desordem depressiva recorrente (Organização Mundial da Saúde, 2007). 
A depressão é uma das patologias mais comuns nos dias de hoje, com uma prevalência relatada de até $15 \%$ na população mundial para o transtorno depressivo maior, embora em alguns países sua importância epidemiológica seja ainda dificilmente reconhecida (Kessler et al., 2007). Aqueles que sofrem de depressão podem ter um prejuízo significativo nas suas atividades diárias e relações pessoais; possuem um risco aumentado de mortalidade direta (suicídio) e indireta (comorbidade com outras doenças). O Global Burden of Disease Study identifica os transtornos de depressão como entre os maiores casos de incapacidade produtiva e também como doenças que representarão um crescente problema de saúde pública e sócioeconômico mundial nos próximos anos (Murray e Lopez, 1997). Além disso, o European Brain Council estima um custo anual para as desordens de humor (depressão, transtorno bipolar, ciclotimia e distimia) de 106 bilhões de euros, com uma prevalência de 21 milhões de pessoas espalhadas pelos 28 países da Europa (Olesen et al., 2006).

Apesar dos avanços dos últimos 50 anos nas pesquisas em relação aos transtornos afetivos e seu tratamento, grande obscuridade ainda paira sobre o entendimento de sua neurobiologia. Devido à grande importância sócio-econômica dos transtornos depressivos, e acima disso, ao sofrimento individual e também do círculo social próximo das pessoas que sofrem desses transtornos, há necessidade da realização de estudos a respeito da neurobiologia da depressão a fim de se compreender os mecanismos que levam ao desenvolvimento deste transtorno e, eventualmente, desenvolver métodos mais eficazes de tratamento.

\subsection{Neurobiologia da Depressão}

As causas e processos envolvidos na gênese da depressão ainda não são totalmente esclarecidos e muitos avanços ocorreram nos últimos anos na busca por essa elucidação. Sabe-se que a depressão possui um componente genético bastante importante (Sullivan et al., 2000), 
principalmente nas formas mais severas de depressão (Baldwin, 2002). Há evidências, por exemplo, de que um polimorfismo no gene que codifica o transportador da serotonina (5-HTT) seja capaz de aumentar a sensibilidade de indivíduos a eventos aversivos e, assim, predispor indivíduos ao desenvolvimento de transtornos afetivos (Caspi et al., 2003). Contudo, esse polimorfismo não seria suficiente para causar a depressão, tendo apenas um caráter modulatório sobre o fator ambiental. Efeitos semelhantes já foram descritos para outros polimorfismos em genes relacionados à neurotransmissão monoaminérgica, porém nenhum gene foi até agora reconhecido como um fator determinante para a ocorrência da doença, tamanha a complexidade do mecanismo genético envolvido (Nestler et al., 2002; Holmans et al., 2007).

Diante disso, observa-se que o componente ambiental possui também grande importância no desenvolvimento da depressão e dos demais transtornos afetivos. Dentre esses fatores, o estresse tem recebido especial importância. Há evidências de que, em cerca de $60 \%$ dos casos, os episódios depressivos são precedidos pela ocorrência de fatores estressantes, principalmente os de origem psicossocial, sugerindo o envolvimento do estresse em sua etiologia (Post, 1992). De fato, a depressão é freqüentemente descrita como uma desordem relacionada ao estresse, com vasta citação bibliográfica que coloca o estresse como o principal fator capaz de predispor ao desenvolvimento de transtornos depressivos (Post, 1992; Kendler et al., 1995; Nestler et al., 2002; McEwen, 2004; Southwick et al., 2005; Pittenger e Duman, 2008).

Devido a essa estreita relação entre estresse e depressão, a maioria dos modelos animais para o estudo desse transtorno é baseada na exposição de animais a situações estressantes inescapáveis de diferentes naturezas. Essa exposição resulta em mudanças comportamentais que pretendem simular alguns aspectos dos transtornos depressivos e que sejam reversíveis pelo tratamento com drogas antidepressivas (Willner e Mitchell, 2002). A utilização desses modelos tem sido muito importante na busca de possíveis novas abordagens 
terapêuticas, bem como na investigação de aspectos que ainda não são totalmente compreendidos sobre a neurobiologia da depressão.

A principal teoria sobre a neurobiologia da depressão é conhecida como a "Teoria monoaminérgica clássica da depressão". Essa teoria foi baseada nas propostas de J. Schildkraut (1965) e de Lapin e Oxenkrug (1969) e, de acordo com esta, deficiências na neurotransmissão noradrenérgica e/ou serotoninérgica, em determinados sítios funcionalmente importantes no encéfalo, seriam a causa de desordens como a depressão (Schildkraut, 1965; Lapin e Oxenkrug, 1969; Castrén, 2005). Porém, alguns achados levam a questões que não podem ser resolvidas por essa correlação tão simples. Por exemplo, a depleção aguda de triptofano, o precursor da serotonina, causa diminuição dos níveis de serotonina no encéfalo, porém não tem efeitos ou causa apenas uma leve disforia em pacientes saudáveis (Delgado, 2004; Booij et al., 2003). A hipótese também não explica por que são necessárias várias semanas de tratamento continuado com drogas antidepressivas para que seus resultados clínicos apareçam, uma vez que seus efeitos sobre a neurotransmissão monoaminérgica são vistos logo após a administração dessas drogas (Nestler, 1998). Além disso, cerca de $45 \%$ dos pacientes são resistentes ao tratamento farmacológico clássico (Keks et al., 2007), o que mostra que a depressão não deve ser encarada como uma desordem simples e unitária, dependente apenas das concentrações de monoaminas (Katz et al., 2010).

Avanços nas pesquisas deram origem a novas abordagens para a neurobiologia da depressão e uma das principais é a "Hipótese Neurotrófica” (Castrén, 2005). Dde acordo com essa hipótese, a depressão seria causada não simplesmente por uma depleção de monoaminas, mas por alterações plásticas envolvendo um prejuízo nas funções mediadas por neurotrofinas, como o fator neurotrófico derivado do cérebro (o BDNF - Brain Derived Neurotrophic Factor), o que levaria a disfunções nas redes neurais causando um prejuízo funcional que levaria também a um desequilíbrio monoaminérgico nas estruturas límbicas (Castrén, 2005). As neurotrofinas regulam o 
crescimento neural e a diferenciação ao longo do desenvolvimento cerebral; regulam a plasticidade dos neurônios e das células gliais; e são importantes nas respostas aos danos neuroniais, na manutenção das conexões funcionais entre as células e na neurogênese (Nestler, 2002).

Tal hipótese está fundamentada em estudos que indicam que o estresse é capaz de diminuir e o tratamento com drogas antidepressivas aumentar significativamente a expressão de BDNF nas regiões límbicas, em especial no hipocampo (Duman et al, 2006). Além disso, o estresse promove diminuição da produção e da sobrevivência de novos neurônios no hipocampo (Gould et al., 1997; Gould e Tanapat, 1999; Tanapat et al., 2001; Malberg e Duman, 2003), bem como reduções no comprimento de espinhos dendríticos e também na arborização de neurônios piramidais hipocampais (McKittrick et al., 2000), efeitos que são atenuados em animais tratados cronicamente com drogas antidepressivas (Duman et al., 2006). Recentemente, foi demonstrado que o efeito comportamental de drogas antidepressivas depende dos níveis de BDNF no giro denteado do hipocampo (Adachi et al., 2010), bem como da neurogênese (Santarelli et al, 2003), uma vez que o bloqueio local dessa neurotransmissão, ou da neurogênese, impede o aparecimento do efeito tipo-antidepressivo em modelos animais

Porém, mesmo com o surgimento dessas novas hipóteses, o entendimento a respeito dos mecanismos moleculares e neurotransmissores envolvidos na neurobiologia da depressão ainda não estão completamente elucidados.

\subsection{Hipocampo e Depressão}

Inúmeros trabalhos apontam o hipocampo como uma das principais estruturas cerebrais envolvidas nos processos de adaptação ao estresse (Shumake et al., 2002; Joca et al., 2003b; Seidenbecher et al., 2003) e na neurobiologia da depressão (Lee et al., 2002; Sheline et al., 2002; Campbell e MacQueen, 2004). 
Primeiramente, sabe-se que o estresse promove ativação do eixo hipotálamo-pituitáriaadrenal (eixo HPA), que leva a liberação de glicocorticóides pela supra-renal. Dependendo da duração e da intensidade do estresse, pode haver uma elevação sustentada dos níveis de corticóides, os quais podem promover vários efeitos deletérios ao organismo, incluindo morte celular (Lee et al., 2002; Lucassen et al., 2001a) e redução da expressão de neurotrofinas (Nestler, 2002), por exemplo. Essas alterações podem tornar o indivíduo mais susceptível ao desenvolvimento de distúrbios psiquiátricos, como a depressão (McEwen, 2007; Joels, 2008) e, de fato, o eixo HPA se encontra desregulado em grande parte dos indivíduos depressivos (McEwen, 2007; Joels, 2008). Portanto, a regulação da atividade do eixo HPA parece ter um papel importante no controle da resposta endócrina e emocional ao estresse.

Nesse sentido, o hipocampo é a região encefálica com a maior densidade de receptores para corticosteróides (receptores glicocorticóides e mineralocorticóides; McEwen et al., 1968; Gerlach e McEwen, 1975; de Kloet, 2000), os quais quando ativos contribuem para a redução da atividade do eixo HPA (Bremmer, 1999). Por outro lado, como importante alvo para os efeitos dos glicocorticóides, o hipocampo também está sujeito aos seus efeitos prejudiciais, de modo que níveis sustentados de corticóides induzem danos estruturais no hipocampo decorrentes de diminuição da arborização dendrítica, indução de apoptose e diminuição da neurogênese local (Lucassen et al., 2001; Lee et al., 2002; Santarelli et al., 2003; Czeh e Lucassen, 2007). Tais alterações estruturais, por sua vez, poderiam prejudicar as funções desempenhadas pelo hipocampo, favorecendo o desencadeamento de alterações comportamentais e afetivas.

Durante situações de estresse, o hipocampo estaria envolvido em um sistema de detecção e resolução de conflitos do tipo "approach-avoidance” ou aproximação x esquiva. Quando há um conflito deste tipo, o hipocampo faria parte do sistema que calcula se a recompensa em se aproximar do alvo (entrar num lugar desconhecido em busca de alimento, por exemplo) é maior 
ou menor do que os riscos que o indivíduo será submetido, e emite um sinal que aumenta o valor afetivo negativo, diminuindo a tendência à aproximação e, assim, favorecendo a preservação do indivíduo (Gray e McNaughton, 2000). Nesse contexto, alterações funcionais no hipocampo poderiam, por exemplo, favorecer a formação de associações negativas contribuindo assim para o desenvolvimento das consequências comportamentais do estresse.

Deakin e Graeff (1991) postularam a hipótese que a depressão seria causada por um desequilíbrio de receptores serotoninérgicos no hipocampo, provavelmente por uma deficiência na neurotransmissão mediada por receptores $5 \mathrm{HT}_{1 \mathrm{~A}}$. Segundo essa teoria, os receptores $5 \mathrm{HT}_{1 \mathrm{~A}}$ pós-sinápticos, presentes em alta concentração na formação hipocampal (Verge et al., 1986; Lundberg et al., 2007), seriam responsáveis por um mecanismo de desconexão de eventos aversivos de suas conseqüências emocionais frente a situações de estresse repetido, por inibirem a consolidação de memórias aversivas, levando o animal a se adaptar àquela situação estressante e desempenhar normalmente suas atividades habituais. Esse sistema funcionaria então como modulador das respostas do organismo frente a eventos aversivos persistentes, permitindo sua adaptação (Graeff et al., 1996). Situações de estresse incontrolável e hipercortisolemia poderiam prejudicar o funcionamento desse mecanismo e, assim, predispor ao desenvolvimento das conseqüências comportamentais do estresse, como o desamparo em animais e a depressão em humanos (Graeff et al., 1996; Joca et al., 2003a).

De fato, há evidências de que os receptores $5 \mathrm{HT}_{1 \mathrm{~A}}$ encontram-se diminuídos no hipocampo de indivíduos com transtornos depressivos (Lopez et al., 1998; Drevets et al., 2000; Bhagwagar et al., 2004; Lopez-Figueroa et al., 2004; Hirvonen et al., 2008; Savitz et al., 2009). Ainda, corroborando essa hipótese, vários trabalhos indicam que os receptores $5-\mathrm{HT}_{1 \mathrm{~A}}$ hipocampais, os quais se co-localizam com receptores para glicocorticóides, encontram-se diminuídos em animais expostos ao estresse crônico ou a tratamento crônico com glicocorticóides (Chalmers et al,. 1994; Lopez et al,. 1998; Karten et al,. 1999; van Riel et al., 2003 e 2004; 
Flugge, 1995 e Flugge et al., 1998). Além disso, em ratos da linhagem sensível de Flanders (FSL - Flanders sensitive line), uma linhagem de animais considerada geneticamente "depressive-like", foi encontrada redução na quantidade de receptores $5 \mathrm{HT}_{1 \mathrm{~A}}$ no hipocampo (Eriksson et al., 2011). Por outro lado, o tratamento crônico com antidepressivos atenua tais efeitos (Blier et al., 1987; Chaput et al., 1991; Invernizzi et al., 1994; Stahl, 1994; Kreiss e Lucki 1995; Lerer et al., 1999; Pineyro e Blier, 1999; Riad et al., 2004; Giovacchini et al., 2005; Rausch et al., 2006) e também parece aumentar a sensibilidade dos receptores pós-sinápticos $5 \mathrm{HT}_{1 \mathrm{~A}}$ em estruturas límbicas como o hipocampo (Hayakawa et al., 1994; Ishihara et al., 1999; Szabo e Blier, 2001). Segundo Blier (Pineyro e Blier, 1999; Szabo e Blier, 2001), a latência para o aparecimento do efeito antidepressivo estaria relacionada a esse aumento da resposta mediada por receptores $5 \mathrm{HT}_{1 \mathrm{~A}}$ póssinápticos em estruturas prosencefálicas como o hipocampo. Dados do nosso grupo dão sustentação ao conjunto de dados escritos acima ao demonstrar que a facilitação da neurotransmissão serotoninérgica no hipocampo dorsal, após o estresse, previne o desenvolvimento de desamparo aprendido em ratos (Joca et al., 2006), um feito tipoantidepressivo, de maneira dependente da ativação de receptores $5 \mathrm{HT}_{1 \mathrm{~A}}$ pós sinápticos presentes nesta área (Joca et al., 2003a).

Mais recentemente, tem-se discutido que outros neurotransmissores, tais como glutamato e óxido nítrico (NO), presentes na formação hipocampal também participariam da regulação dos processos emocionais mediados no hipocampo (Joca et al., 2007).

\subsection{NO e Depressão}

Desde a descoberta do NO como neurotransmissor no sistema nervoso central (SNC; Garthwaite et al., 1988), seu envolvimento em vários processos neurais fisiológicos e relacionados a transtornos psiquiátricos tem sido amplamente investigado (Calabrese et al., 
2007), incluindo evidências do seu envolvimento na neurobiologia da depressão (McLeod et al., 2001).

O estímulo primário para a síntese de NO no SNC é o influxo de cálcio que ocorre principalmente em resposta à ativação de receptores para glutamato do tipo N-metil-D-aspartato (NMDA - Garthwaite et al., 1988). O cálcio leva à ativação da isoforma neuronial da sintase de NO (nNOS) que cataliza a formação de L-citrulina e NO, a partir de L-arginina (Knowles et al., 1989). O NO difunde-se rapidamente pelas células nervosas e pode agir de diversas maneiras, sendo a mais comum delas a ativação da guanilato ciclase solúvel (sGC) seu principal alvo, ou devido à interação com resíduos de cisteína ou tirosina em outras moléculas proteicas (Prast e Philippu, 2001). Como resultado, o NO pode modular a excitabilidade neuronial e também diversos sistemas neurotransmissores (Prast e Philippu, 2001).

Tem sido demonstrado por grupos independentes que a administração de antagonistas dos receptores NMDA induz efeitos do tipo antidepressivo em animais submetidos ao teste do nado forçado. Esse efeito foi observado pioneiramente com a administração de MK801 (Trullas e Skolnick, 1990; Maj et al, 1992a) e ACPC (Ácido 1-aminociclopropanocarboxílico - um antagonista funcional dos receptores do tipo NMDA; Trullas e Skolnick 1990). Efeitos semelhantes foram observados também com a administração de AP7 (ácido 2-amino-7fosfonoheptanóico - antagonista competitivo dos receptores NMDA; Trullas e Skolnick, 1990), eliprodil (um antagonista NMDA que age no sítio poliamínico do receptor; Layer et al., 1995), CGP37849 (antagonista competitivo dos receptores NMDA; Maj et al., 1992b) e, mais recentemente, com ketamina (antagonista NMDA não competitivo; Li et al., 2010 e 2011). Além disso, Przegalinski e cols. (1997) administraram CGP 37849 e ACPC diretamente no hipocampo de ratos e observaram efeitos do tipo antidepressivo similares aos encontrados com a administração sistêmica ou local de imipramina, um antidepressivo tricíclico, indicando um provável sítio de ação no SNC para essas drogas. 
Efeitos do tipo antidepressivo induzidos por antagonistas NMDA também foram descritos em trabalhos que empregaram outros testes e modelos animais utilizados para o estudo de comportamentos relacionados à depressão, como o teste de suspensão pela cauda (TST- Tail Suspension Test; Panconi et al., 1993), o modelo de desamparo aprendido (Meloni et al., 1993) e o modelo do estresse crônico variado imprevisível (CUMS - Chronic Unpredictable Mild Stress; Papp e Moryl, 1993; Papp e Moryl, 1994).

Em adição a esses dados, há relatos de que o tratamento repetido com antagonistas NMDA induz down-regulation dos receptores $\beta$-adrenérgicos corticais em roedores (Paul et al., 1992; Klimek e Papp, 1994), um efeito característico observado após o tratamento crônico com drogas antidepressivas (Nimgaonkar et al., 1985; Paul et al., 1992). Além disso, o tratamento crônico com drogas antidepressivas reduz a expressão de receptores NMDA em várias estruturas encefálicas, em particular no córtex pré-frontal e no hipocampo (Sanacora et al., 2008). Assim, em conjunto, esses dados indicam que a redução da neurotransmissão mediada por receptores NMDA para glutamato em estruturas límbicas estaria envolvida com o aparecimento de efeitos do tipo antidepressivo. Em outras palavras, o aumento da neurotransmissão mediada por glutamato parece favorecer o desenvolvimento de conseqüências comportamentais do estresse em animais e, possivelmente, a depressão em humanos (Sanacora et al., 2008).

Considerando que a principal via de formação do NO no SNC ocorre via ativação de receptores NMDA, os trabalhos supracitados levaram à formulação da hipótese de que o NO poderia estar envolvido no desenvolvimento das conseqüências comportamentais induzidas pelo estresse. Essa hipótese ganhou sustentação ao se demonstrar que a inibição da síntese de NO através da administração sistêmica de inibidores não seletivos da NOS também induz efeito tipo antidepressivo em roedores submetidos ao teste do nado forçado (Jefferys e Funder, 1996; Yildiz et al., 2000; Heiberg et al., 2002; Harvey et al., 2010). Mais recentemente, outros modelos animais foram empregados, como o desamparo aprendido (Stanquini et al., 2008), o estresse crônico variado imprevisível (Zhang et al., 2008) e outros tipos de estresse (Khovryakov et al., 
2010), onde o tratamento com inibidores da NOS induziu efeitos do tipo antidepressivo, reforçando a idéia da participação do NO na neurobiologia da depressão.

Corroborando esses dados, foi relatado aumento da expressão da nNOS no hipocampo de humanos deprimidos (Oliveira et al., 2008), além de níveis séricos de nitratos elevados (Suzuki et al., 2001), o que pode ser um indicativo de aumento de produção de NO nesses pacientes. Além disso, a inibição da via NOS/sGC com azul de metileno promoveu significativa melhora do humor em pacientes deprimidos (Naylor et al., 1987).

Embora ainda não sejam bem conhecidos os aspectos moleculares e neuroquímicos envolvidos no efeito antidepressivo induzido pelos inibidores da NOS, evidências recentes sugerem um provável envolvimento do sistema serotoninérgico. Nesse sentido, foi demonstrado que os efeitos comportamentais do tipo antidepressivo induzido pelos inibidores da NOS são dependentes de serotonina endógena, uma vez que a inibição da síntese de serotonina bloqueou os efeitos do tipo antidepressivo induzido pelo tratamento sistêmico com essas drogas (Harkin et al., 2003). Em outro trabalho do mesmo grupo (Harkin et al., 2004), foi demonstrado que a administração de doses subefetivas de inibidores da NOS potencializou o efeito antidepressivo de inibidores seletivos de recaptação de serotonina, mas não o efeito de drogas inibidoras seletivas de recaptação de noradrenalina. Mais recentemente, Gigliucci e cols. (2010) demonstraram que a administração concomitante de um antagonista serotoninérgico não seletivo atenuou o efeito do tipo antidepressivo induzido pela administração sistêmica de um inibidor da NOS em animais submetidos ao teste do nado forçado. Assim, o conjunto de dados sugere que os efeitos do tipo antidepressivo induzidos pelos inibidores da NOS administrados sistemicamente envolvam uma facilitação da neurotransmissão serotoninérgica no SNC.

Contudo, pouco se sabe a respeito das estruturas encefálicas envolvidas em tais efeitos. Dados da literatura apontam para um provável envolvimento da formação hipocampal, uma vez que a administração intra-hipocampo dorsal de antagonista NMDA (Padovan e Guimarães, 2004) ou de inibidor da NOS (Joca e Guimarães, 2006) induz efeito tipo-antidepressivo em animais submetidos ao teste do nado forçado. 
Wegener e seu grupo de pesquisa demonstraram que NO endógeno diminui os níveis de serotonina no hipocampo (Wegener et al., 2000), e também que a administração de antidepressivos serotoninérgicos diretamente no hipocampo de ratos diminui a atividade da enzima NOS (Wegener et al., 2003), indicando assim possíveis interações entre as vias nitrérgica e serotoninérgica nessa estrutura cerebral.

Portanto, considerando que o efeito antidepressivo induzido pela administração sistêmica de inibidores da NOS depende de serotonina (Harkin et al., 2003) e que a administração intra-hipocampal de drogas que facilitam a neurotransmissão mediada pela serotonina (Joca et al., 2003) ou diminuem NO (Joca e Guimaraes, 2006) induz efeitos do tipo antidepressivo em animais submetidos ao teste do nado forçado, pode ser sugerido que esse último efeito dependeria dos níveis de serotonina no hipocampo. Ainda, considerando que o aumento de serotonina no hipocampo promove efeitos antidepressivos por meio da ativação de receptores 5- $\mathrm{HT}_{1 \mathrm{~A}}$, deveríamos esperar que o efeito antidepressivo obtido com a administração intra-hipocampal de inibidor da nNOS fosse atenuado pelo pré-tratamento com antagonista de receptores serotoninérgicos, especialmente do tipo 5-HT $\mathrm{HA}_{1 \mathrm{~A}}$.

\subsection{Hipótese}

Os dados levantados anteriormente nos levaram à hipótese de que o aumento de NO no hipocampo facilitaria o desenvolvimento das conseqüências comportamentais do estresse por prejudicar a neurotransmissão serotoninérgica local e, conseqüentemente, a ativação de receptores $5-\mathrm{HT}_{1 \mathrm{~A}}$. Ou seja, o efeito do tipo antidepressivo induzido pela administração de inibidores de NOS no hipocampo dorsal em ratos envolveria o aumento local das concentrações de serotonina e, subseqüentemente, a ativação de receptores $5 \mathrm{HT}_{1 \mathrm{~A}}$ nessa estrutura. 
OBJETIVOS 


\section{OBJETIVOS}

\subsection{Objetivo geral}

Testar a hipótese de que o efeito do tipo antidepressivo induzido pela administração de inibidores de NOS no hipocampo dorsal em ratos seriam dependentes do aumento de serotonina e da subseqüente ativação dos receptores serotoninérgicos do tipo $5 \mathrm{HT}_{1 \mathrm{~A}}$ nessa região encefálica.

\subsection{Objetivos específicos}

i. Avaliar se a inibição da nNOS no hipocampo dorsal, através da administração local de inibidor seletivo de nNOS (NPA), induziria efeito tipo antidepressivo em ratos submetidos ao teste do nado forçado.

ii. Avaliar se a inibição da recaptação de serotonina no hipocampo dorsal, através da administração local de fluoxetina induziria efeito tipo antidepressivo em ratos submetidos ao teste do nado forçado.

iii. Avaliar se o pré-tratamento com antagonista seletivo de receptores $5-\mathrm{HT}_{1 \mathrm{~A}}$ (WAY100635) bloquearia os efeitos induzidos pela administração intrahipocampal de fluoxetina.

iv. Avaliar se o pré-tratamento com antagonista seletivo de receptores $5-\mathrm{HT}_{1 \mathrm{~A}}$ (WAY100635) bloquearia os efeitos induzidos pela administração intrahipocampal de NPA. 
MATERIAL E MÉTODOS 


\section{MATERIAL E MÉTODOS}

\subsection{Animais}

Foram utilizados ratos Wistar (200 a 220 gramas no momento da cirurgia), provenientes do Biotério Central do Campus da USP-RP, os quais foram mantidos aos pares em gaiolas de acrílico $\left(570 \mathrm{~cm}^{2}\right)$ no biotério do Laboratório de Farmacologia da Faculdade de Ciências Farmacêuticas de Ribeirão Preto-USP, em condições controladas: temperatura $\left(25 \pm 1^{\circ} \mathrm{C}\right)$, ciclo de luz (acesas das 6:00 às 18:00 horas), alimento e água ad libitum. Os experimentos realizados foram aprovados pelo comitê de ética local (protocolo No. 08.1.1133.53.4) e todos os esforços possíveis para minimizar o sofrimento dos animais foram realizados.

\subsection{Drogas}

Foram utilizadas as seguintes drogas:

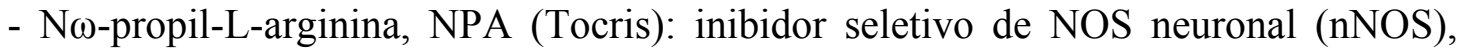
solubilizado em salina isotônica estéril e administrado através de injeção intra-hipocampal bilateral nas doses de $10^{-5}, 10^{-4}$ e $10^{-2} \mathrm{nmol} / 0.5 \mu \mathrm{L} / \mathrm{lado}$, de acordo com dados prévios do laboratório.

- WAY100635 - Antagonista 5HT $1 \mathrm{~A}$ seletivo, solubilizado em salina isotônica estéril e administrado através de injeção intra-hipocampal bilateral nas doses de 1, 3, $10 \mathrm{nmol} / 0.5$ $\mu \mathrm{L} /$ lado (Joca et al., 2003a).

- Fluoxetina - Inibidor seletivo de recaptação de serotonina, solubilizado em salina isotônica estéril e administrado através de injeção intra-hipocampal bilateral nas doses de 1, 3 e $10 \mathrm{nmol} / 0,5 \mu \mathrm{L}$, a fim de encontrar uma dose efetiva e uma dose sub-efetiva da droga. 
Além disso, foram utilizados durante os procedimentos cirúrgicos: cetamina 10\%/xilasina 2\% (0,1 mL/100g); Banamine (Schering-Plough, 0,25\%, 0,1 mL/100g), Lidocaína (PROBEM 3\%, 0,2 ml); e pentabiótico veterinário, (Fort Dodge, 1.200.000 UI Benzilpenicilina benzatina 600.000 UI, Benzilpenicilina procaína 300.000 UI, Benzilpenicilina potássica 300.000 UI, Diidroestreptomicina base (sulfato) $250 \mathrm{mg}$ e Estreptomicina base (sulfato) $250 \mathrm{mg}$ ), 0,1 $\mathrm{ml} / 100 \mathrm{~g}$ ).

\subsection{Procedimentos}

\subsubsection{Cirurgia estereotáxica e administração intracerebral de drogas}

Os ratos foram anestesiados com cetamina 10\%/xilasina 2\% (i.p., 1:1) na dose de 0,1 $\mathrm{ml} / 100 \mathrm{~g}$ e fixados na armação estereotáxica (Stoelting). Cânulas-guia (0.7 mm OD) de aço inoxidável foram implantadas bilateralmente e direcionadas para o hipocampo dorsal (coordenadas: ântero-posterior: $-4,0 \mathrm{~mm}$ de lambda, lateral: 2,8 mm, dorsoventral:- 2,1 mm), de acordo com o atlas de Paxinos e Watson (1997). A ponta da cânula permaneceu 1,5 mm acima do local da injeção e as cânulas prenderam-se ao osso do crânio por parafusos de aço e cimento acrílico. Um mandril foi colocado em cada cânula guia para evitar sua obstrução. Apos os procedimentos cirúrgicos, os animais receberam administração de pentabiótico veterinário (i.m., 0,1mL/100g) e do antiinflamatório Banamine (s.c. 0,1mL/100g), com o objetivo de evitar quadros infecciosos e reduzir a dor pós-operatória.

Ao final da cirurgia, os animais foram acondicionados em uma gaiola com aquecimento, onde permaneceram sob observação por 30 minutos. Apos esse período, os animais retornaram as suas gaiolas, onde permaneceram em repouso por 5-7 dias. Apos esse período, foram realizados os experimentos comportamentais e as injeções intra-hipocampais, 
as quais foram administradas com por meio de agulhas dentarias $(0.3 \mathrm{~mm}$ OD) introduzidas bilateralmente através da cânula guia ( $1.5 \mathrm{~mm}$ abaixo do fìm da cânula). Foi administrado um volume de $0.5 \mu \mathrm{L} /$ lado, durante 1 minuto, usando uma microsseringa controlada por uma bomba de infusão (Insight, BR).

\subsubsection{Análise Histológica dos sítios de administração de drogas}

Ao término dos experimentos comportamentais, os ratos foram anestesiados com hidrato de cloral e perfundidos com salina isotônica seguida por solução de formalina $10 \%$. Após a perfusão, uma agulha dentaria foi inserida na cânula guia para administração de $0.2 \mu l$ do corante azul de Evans, bilateralmente. Os cérebros foram removidos e imersos em solução de formalina $10 \%$, a fim de serem posteriormente (no mínimo 5 dias) seccionados em criostato (Cryocut 1800, $-18{ }^{\circ} \mathrm{C}$ ) numa espessura de $40 \mu \mathrm{m}$. Os sítios das injeções foram registrados em diagramas do Atlas de Paxinos e Watson (1997), sendo desconsiderados da análise estatística os dados dos animais cujo local da injeção se encontraram fora do hipocampo dorsal.

\subsubsection{Teste do nado forçado}

O teste do nado forçado é um teste que foi desenvolvido por Roger D. Porsolt e seu grupo (Porsolt et al., 1977; Porsolt et al., 1978) e que consiste em colocar individualmente os animais bem um cilindro de acrílico $(30 \mathrm{~cm}$ de diâmetro, $40 \mathrm{~cm}$ de altura, contendo $25 \mathrm{~cm}$ de água a $24 \pm 1{ }^{\circ} \mathrm{C}$, modificado por Joca e Guimarães, 2006) por 15 minutos (sessão de préteste). Vinte e quatro horas depois, os animais são submetidos a uma sessão de 5 minutos de nado forçado (sessão de teste). Durante essa sessão, é registrado o total do tempo em que o 
animal permanece imóvel, bem como o tempo de latência do primeiro episódio de imobilidade. O animal é considerado imóvel quando permanece parado, realizando apenas movimentos suficientes para manter-se sob flutuação. A água é trocada após cada teste, para evitar a interferência do que Abel e Bilitzke (1990) chamaram de substâncias de alarme. Essas substâncias seriam liberadas pelos animais frente a situações aversivas (como o nado forçado) e seriam detectadas por outros animais que mais tarde fossem postos nessa mesma água, interferindo no comportamento do animal.

\subsubsection{Desenho Experimental}

Experimento 1: Efeitos da administração intra-hipocampal de NPA sobre o comportamento de animais submetidos ao teste do nado forçado.

Os ratos foram submetidos à cirurgia estereotáxica e, cinco a sete dias depois, foi realizado o pré-teste. Imediatamente após o pré-teste, os animais receberam uma administração bilateral intra-hipocampo dorsal de NPA $\left(10^{-5}, 10^{-4}\right.$ ou $\left.10^{-2} \mathrm{nmol} / 0,5 \mu \mathrm{L}\right)$, ou de veículo $(0.5$ $\mu \mathrm{L} /$ lado), sendo submetidos ao teste vinte e quatro horas depois. Após o término do teste, os animais foram perfundidos e seus encéfalos removidos para posterior análise dos sítios de injeção.

Experimento 2: Efeitos da administração intra-hipocampal de fluoxetina sobre o comportamento de animais submetidos ao teste do nado forçado.

Os ratos foram submetidos à cirurgia estereotáxica e, cinco a sete dias depois, foi realizado o pré-teste. Imediatamente após o pré-teste, os animais receberam uma administração bilateral intra-hipocampo dorsal de fluoxetina $(1,3$ e $10 \mathrm{nmol} / 0.5 \mu \mathrm{L} / \mathrm{lado})$ ou veículo $(0.5$ $\mu \mathrm{L} /$ lado), sendo submetidos ao teste vinte e quatro horas depois. Após o teste, os animais foram perfundidos e seus encéfalos removidos para posterior análise dos sítios de injeção. 
Experimento 3: Efeitos da administração intra-hipocampal de WAY100635 sobre o comportamento de animais submetidos ao teste do nado forçado.

Este experimento foi realizado para avaliar se o WAY100635 por si só não induziria efeitos comportamentais em animais submetidos ao teste do nado forçado. Os ratos foram submetidos à cirurgia estereotáxica e, cinco a sete dias depois, foi realizado o pré-teste. Imediatamente após o pré-teste os animais receberam uma administração bilateral intrahipocampo dorsal de WAY100635 (1, 3 e $10 \mathrm{nmol} / 0.5 \mu \mathrm{L} / \mathrm{lado})$ ou veículo (0.5 $\mu \mathrm{L} / \mathrm{lado})$, sendo submetidos ao teste vinte e quatro horas depois. Após o teste, os animais foram perfundidos e seus encéfalos removidos para posterior análise dos sítios de injeção.

Experimento 4: Efeitos da pré-administração de WAY100635 sobre os efeitos induzidos pela administração intra-hipocampal de fluoxetina.

Com o intuito escolher uma dose de WAY100635 que fosse capaz de bloquear os efeitos mediados por receptores $5-\mathrm{HT}_{1 \mathrm{~A}}$, fizemos uso de três doses para verificar qual delas bloquearia os efeitos comportamentais induzidos pela administração local de fluoxetina, para assim, determinar a dose que seria usada no experimento subseqüente. Sendo assim, os ratos foram submetidos à cirurgia estereotáxica e, cinco a sete dias depois, foi realizado o pré-teste. Imediatamente após o pré-teste os animais receberam uma administração bilateral intrahipocampo dorsal de veículo $(0,5 \mu \mathrm{L} / \mathrm{lado})$ ou WAY100635 (1, 3 ou $10 \mathrm{nmol} / 0,5 \mu \mathrm{L} / \mathrm{lado})$, seguida de uma administração de veículo $(0,5 \mu \mathrm{L} / \mathrm{lado}$ ) ou fluoxetina (na dose de 10 $\mathrm{nmol} / 0,5 \mu \mathrm{L} / \mathrm{lado}$ ), cinco minutos depois. Vinte e quatro horas depois, os animais foram submetidos ao teste do nado forçado. Após o teste, os animais foram perfundidos e seus encéfalos removidos para posterior análise dos sítios de injeção. 
Experimento 5: Efeitos da pré-administração de WAY100635 sobre os efeitos induzidos pela administração intra-hipocampal de NPA.

Os ratos foram submetidos à cirurgia estereotáxica e, cinco a sete dias depois, ao préteste. Imediatamente após o pré-teste os animais receberam uma administração bilateral intrahipocampo dorsal de veículo (0,5 $\mu \mathrm{L} / \mathrm{lado})$ ou WAY100635 (10 nmol/0,5 $\mu \mathrm{L} / \mathrm{lado})$, seguida de uma administração de veículo (0,5 $\mu \mathrm{L} /$ lado) ou de NPA (dose de $0,0001 \mathrm{nmol} / 0,5 \mu \mathrm{L} / \mathrm{lado}$ ). Vinte e quatro horas depois, os animais foram submetidos ao teste do nado forçado. Após o teste os animais foram perfundidos e seus encéfalos removidos para posterior análise dos sítios de injeção.

\subsection{Análise Estatística}

O efeito dos diferentes tratamentos sobre o tempo total de imobilidade foi comparado utilizando ANOVA de uma via seguida do pós-teste de Dunnett.

Diferenças com $\mathrm{p}<0.0 .5$ foram consideradas significativas. 
RESULTADOS 


\section{RESULTADOS}

A Figura 1 mostra representativamente os locais de administração intra-hipocampo dorsal das drogas utilizadas neste trabalho.

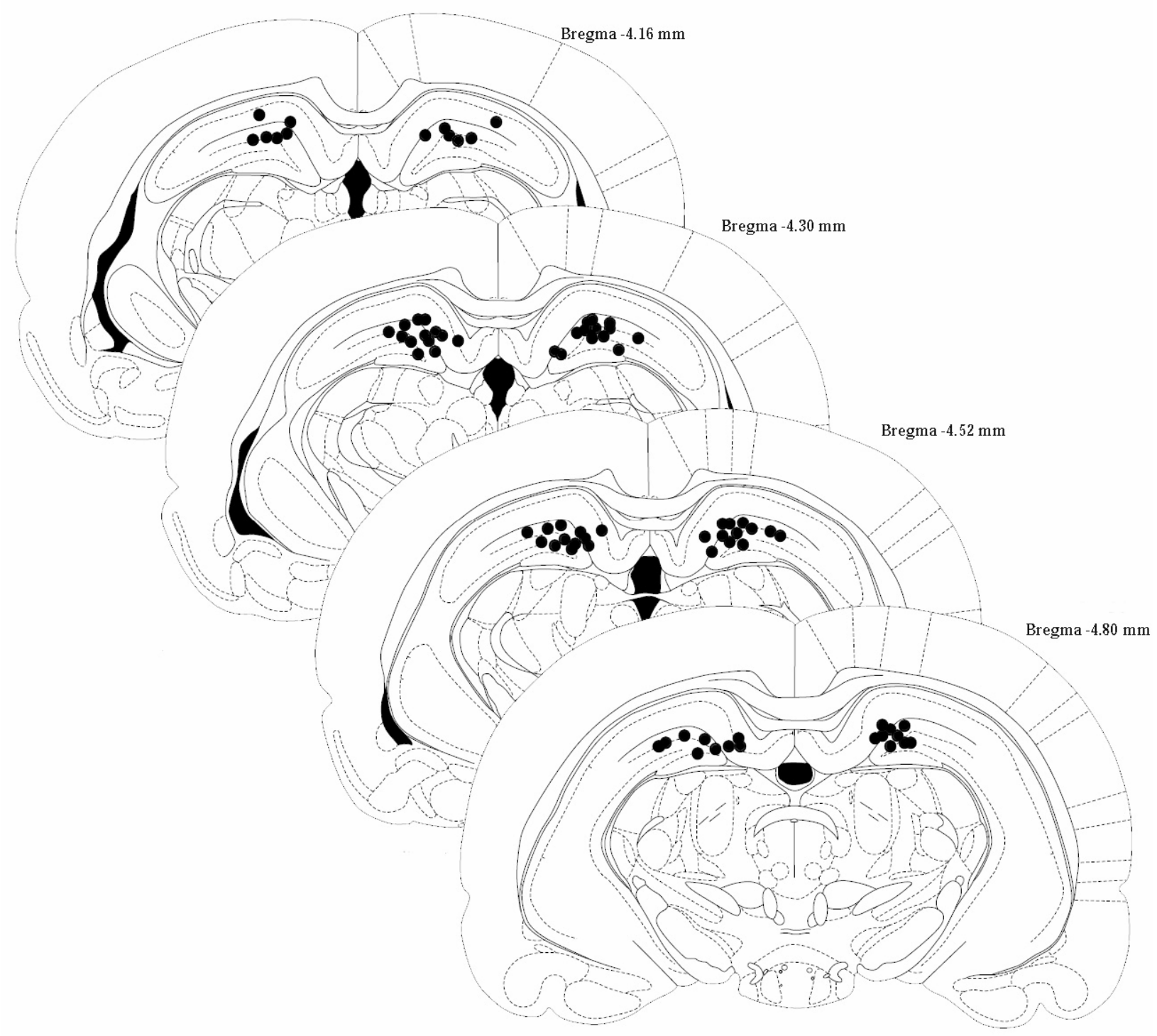

Fig. 01. Diagramas representativos de sítios de administração de drogas no hipocampo dorsal (Diagramas modificados de Paxinos e Watson, 1997). 


\subsection{Efeitos da administração intra-hipocampo dorsal de NPA em ratos submetidos ao} teste do nado forçado

A administração bilateral de NPA no hipocampo dorsal induziu uma diminuição significativa do tempo de imobilidade de ratos submetidos ao teste do nado forçado nas doses de $10^{-5}, 10^{-4}$ e $10^{-2} \mathrm{nmol} / 0,5 \mu \mathrm{L}$ (ANOVA de uma via $\mathrm{F}_{3,21}=5,063 ; \mathrm{p}=0,0086$, pós teste de Dunnett; $\mathrm{p}<0,05$, Fig. 02).

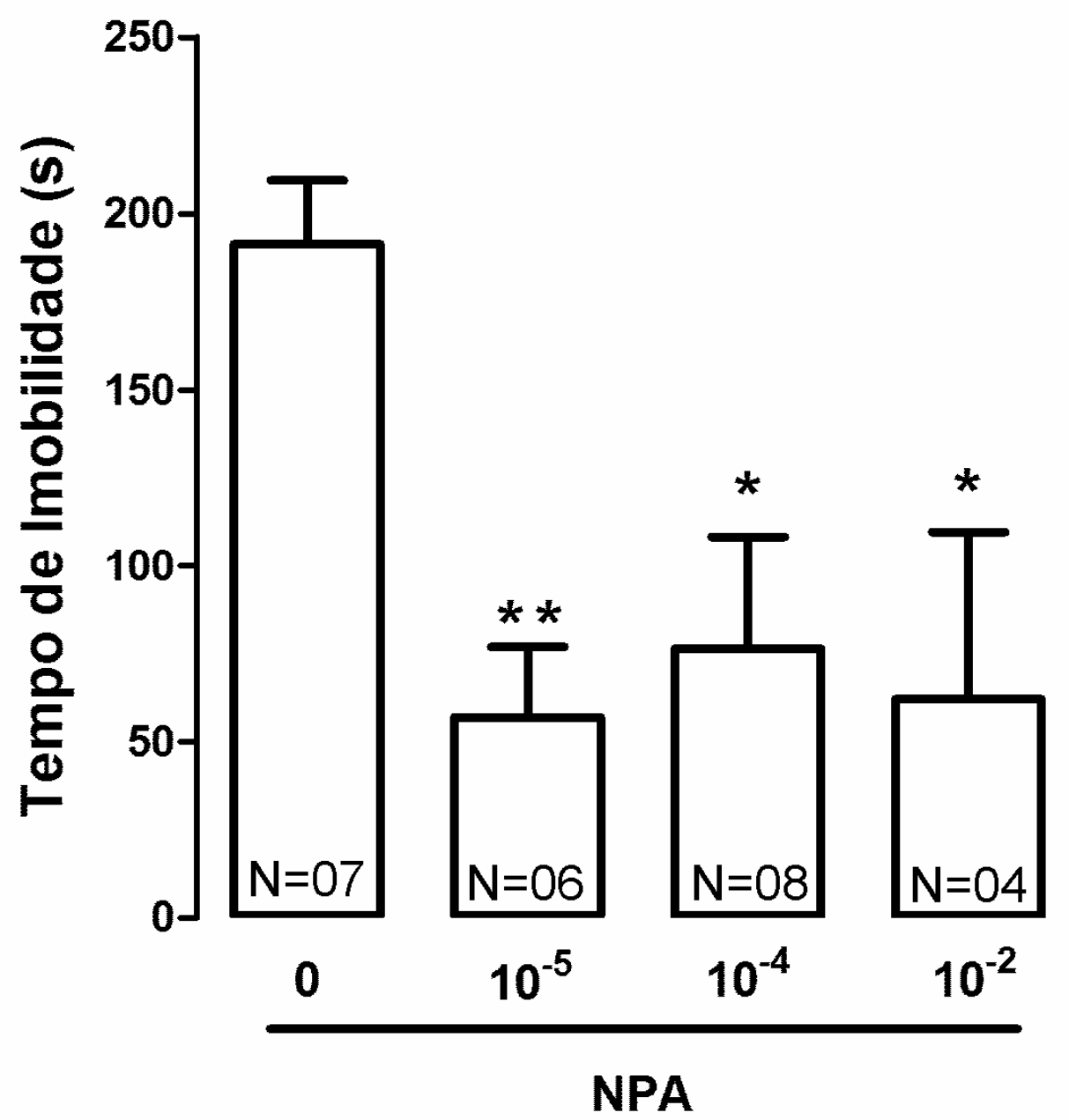

Fig. 02. Administração intra-hipocampal de NPA induz efeitos do tipo antidepressivo em ratos submetidos ao teste do nado forçado. Ratos foram submetidos ao pré-teste e receberam administrações intra-hipocampais de NPA (doses de $10^{-5}, 10^{-4}$ e $10^{-2} \mathrm{nmol} / 0,5 \mu \mathrm{L}$ ) ou veículo $(0,5 \mu \mathrm{L})$. O tempo de imobilidade foi registrado $24 \mathrm{~h}$ depois. Dados representam média $+\mathrm{EPM}, *$ indica $\mathrm{p}<0.05, \mathrm{e}^{* *}$ indica $\mathrm{p}<0.01$, comparado ao grupo controle. NPA - $\mathrm{N}^{\omega}$-Propil-L-arginina. 
4.2. Efeitos da administração intra-hipocampo dorsal de fluoxetina em ratos submetidos ao teste do nado forçado

A administração bilateral de fluoxetina no hipocampo dorsal promoveu uma diminuição no tempo de imobilidade de ratos submetidos ao teste do nado forçado, a qual foi significativa na dose de $10 \mathrm{nmol} / 0,5 \mu \mathrm{L}$ (ANOVA de uma via $\mathrm{F}_{3,29}=3,093 ; \mathrm{p}=0,424$, pós teste de Dunnett, $\mathrm{p}<0,05$ ), mas não nas doses de 1 e $3 \mathrm{nmol} / 0,5 \mu \mathrm{L}$ (pós teste de Dunnett, $\mathrm{p}>0,05$, Fig. 03).

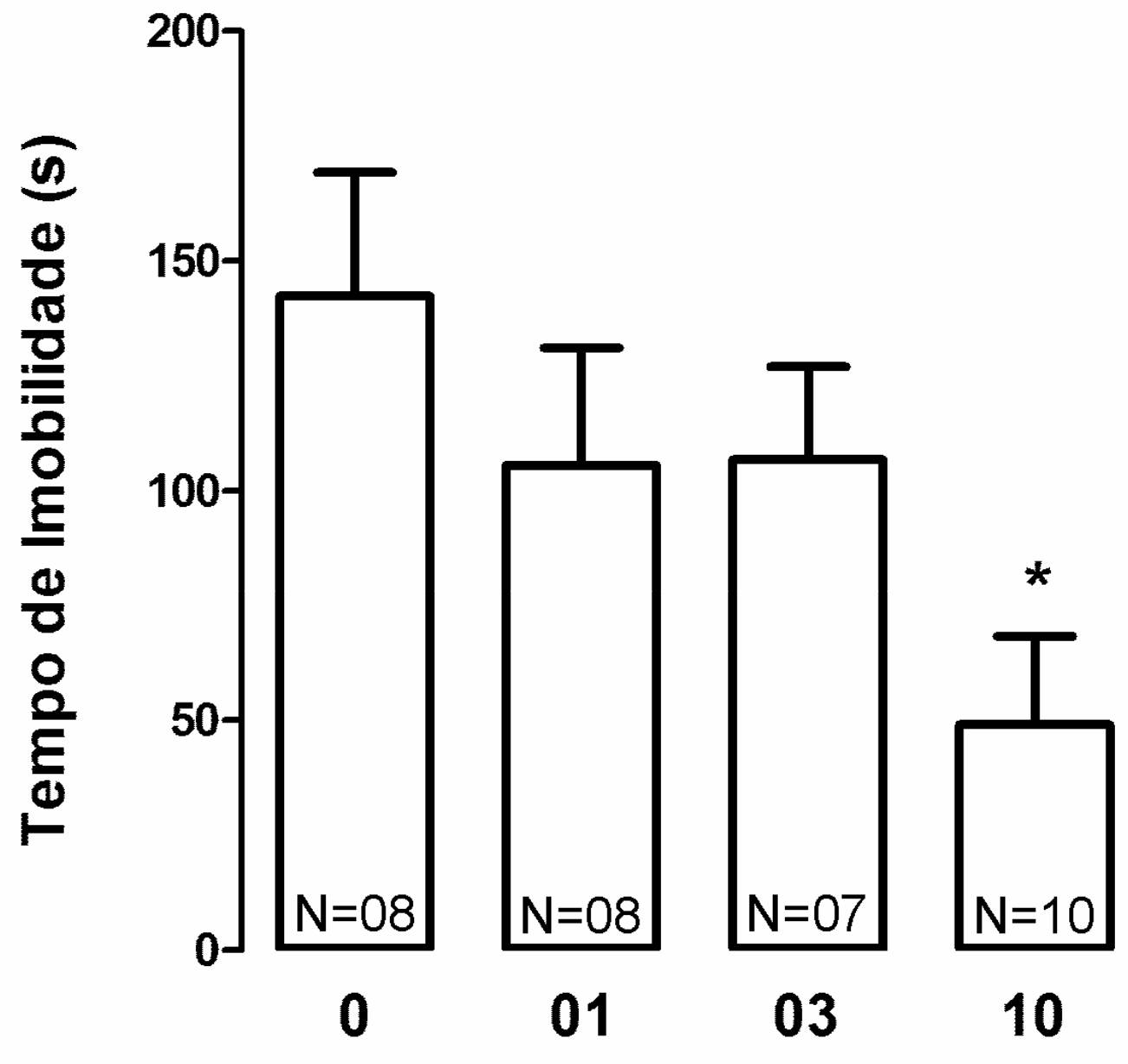

Fluoxetina

Fig. 03. Administração intra-hipocampal de fluoxetina induz efeitos do tipo antidepressivo em ratos submetidos ao teste do nado forçado. Ratos foram submetidos ao pré-teste e receberam administrações intra-hipocampais de fluoxetina $(1,3$ e $10 \mathrm{nmol} / 0,5 \mu \mathrm{L})$ ou veículo $(0,5 \mu \mathrm{L})$. Dados representam média $+\mathrm{EPM}, *$ indica $\mathrm{p}<0.05$, comparado ao grupo controle. 
4.3. Efeitos da administração intra-hipocampo dorsal de WAY100635 em ratos submetidos ao teste do nado forçado

A administração bilateral de WAY100635 não induziu a efeitos significativos por si só em relação ao grupo que recebeu administração de veículo (ANOVA de uma via $F_{3,26}: 0,05979 ; p=0,484 ;$ pós teste de Dunnett, $p>0,05 ;$ Fig. 04).

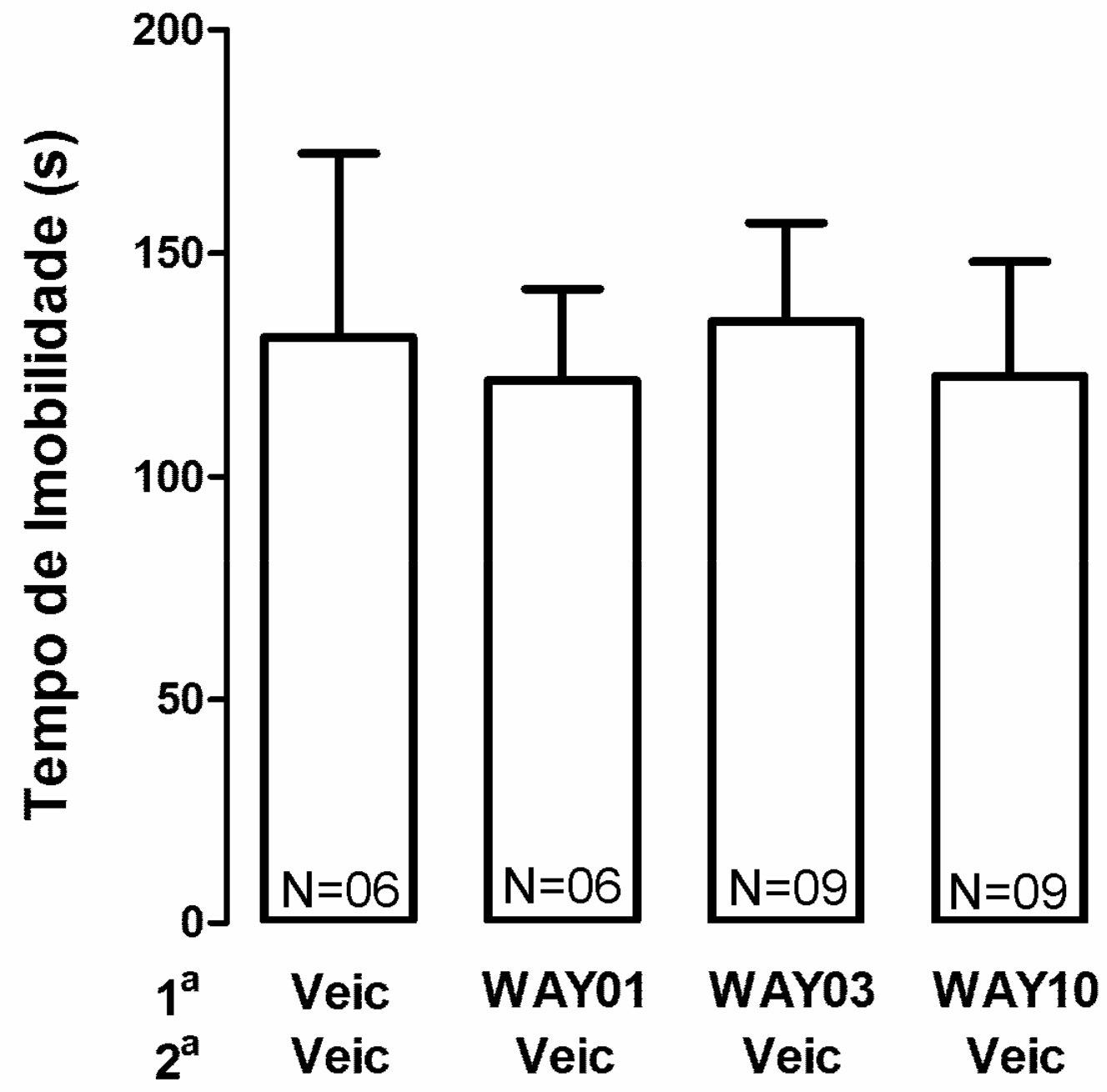

Fig. 04. Administração intra-hipocampal de WAY100635 não altera o comportamento de ratos submetidos ao teste do nado forçado. Ratos foram submetidos ao pré-teste e reberam administrações intra-hipocampais logo após o pré-teste de WAY100635 (1, 3 e $10 \mathrm{nmol} / 0,5 \mu \mathrm{L})$ ou veículo $(0,5 \mu \mathrm{L})$. Dados representam média+EPM. (ANOVA de uma via, $\mathrm{p}>0.05$ ). 
4.4. Efeitos da pré-administração de WAY100635 nos efeitos comportamentais induzidos pela administração de fluoxetina

A pré-administração de WAY100635 foi capaz de bloquear os efeitos comportamentais induzidos pela administração de fluoxetina $(10 \mathrm{nmol} / 0,5 \mu \mathrm{L})$ no hipocampo dorsal de animais submetidos ao teste do nado forçado. Esse efeito foi observado utilizandose a dose de $10 \mathrm{nmol} / 0,5 \mu \mathrm{L}$ (ANOVA de uma via $\mathrm{F}_{4,34}=4,910 ; \mathrm{p}=0,031$, pós teste de Dunnett, $\mathrm{p}>0,05$ ), mas não nas doses de 1 e $3 \mathrm{nmol} / 0,5 \mu \mathrm{L}$ (pós teste de Dunnett, $\mathrm{p}<0,05$, Fig. 05).

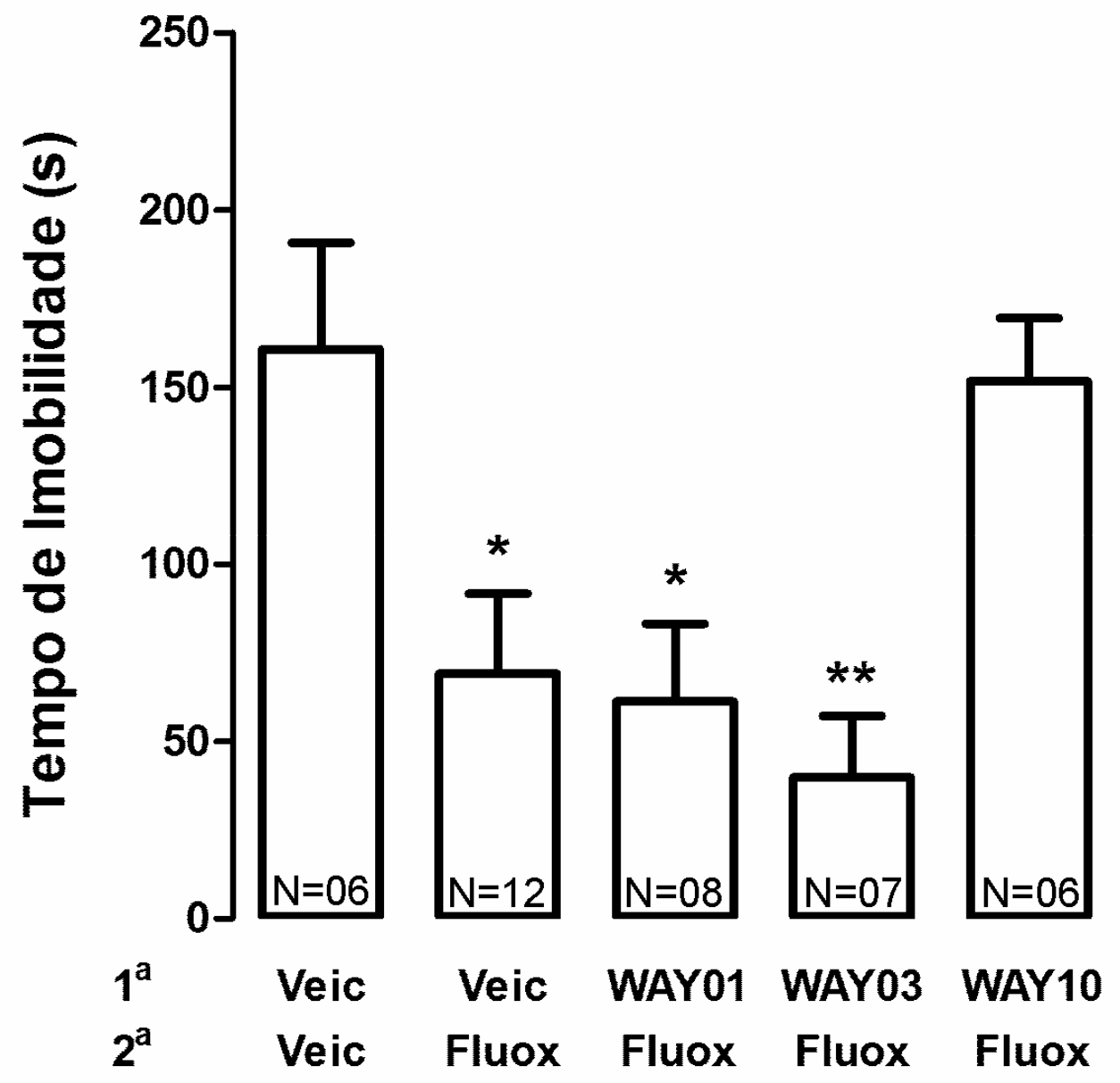

Fig. 05. Pré-administração de WAY100635 bloqueia os efeitos induzidos pela fluoxetina em ratos submetidos ao teste do nado forçado. Ratos foram submetidos ao pré-teste e receberam administrações intra-hipocampais de WAY100635 $(1,3$ e $10 \mathrm{nmol} / 0.5 \mu \mathrm{L})$ ou veículo $(0.5 \mu \mathrm{L})$, e cinco minutos depois receberam também administrações intra-hipocampais de fluoxetina $(10 \mathrm{nmol} / 0.5$ $\mu \mathrm{L})$ ou veículo $(0.5 \mu \mathrm{L})$. Os dados representam a média+EPM. * indica $\mathrm{p}<0.05 \mathrm{e} * *$ indica $\mathrm{p}<0,01$, em relação ao grupo controle. 


\subsection{Efeitos da pré-administração de WAY100635 nos efeitos comportamentais induzidos pela administração de NPA}

A pré-administração de WAY100635 $(10 \mathrm{nmol} / 0,5 \mu \mathrm{L})$ bloqueou os efeitos comportamentais induzidos pela administração de NPA (dose $10^{-4} \mathrm{nmol} / 0,5 \mu \mathrm{L}$ ) no hipocampo dorsal de animais submetidos ao teste do nado forçado (ANOVA de uma via $\mathrm{F}_{2,25}=5,506 ; \mathrm{p}=0,0104$; pós teste de Dunnett: $\mathrm{p}<0,05$ para o grupo NPA e $\mathrm{p}>0.05$ para o grupo NPA + WAY100635; Fig. 06).

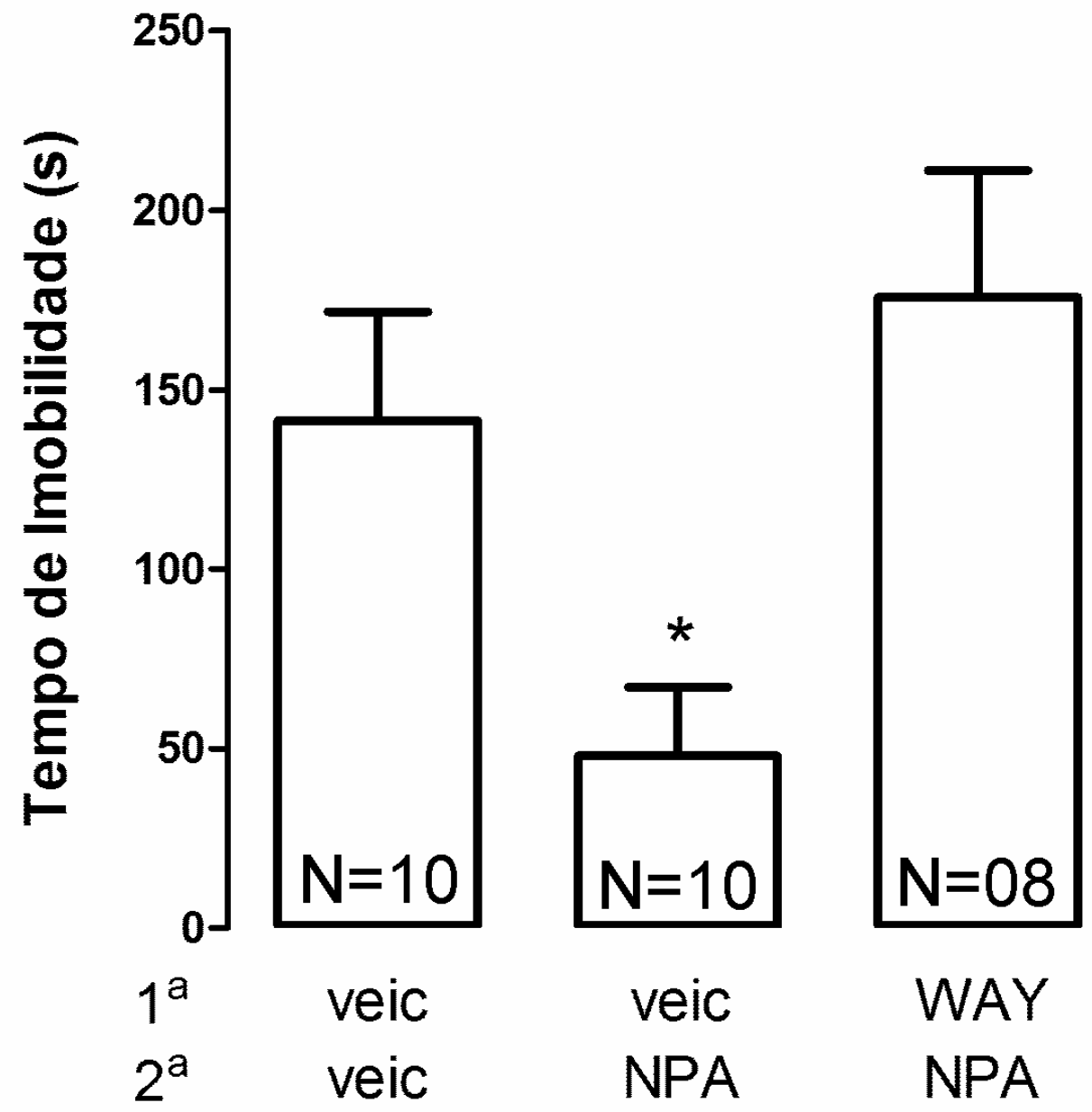

Fig. 06. Pré-administração de WAY100635 bloqueia os efeitos do NPA em ratos submetidos ao teste do nado forçado. Ratos foram submetidos ao pré-teste e receberam administrações intrahipocampais logo após o pré-teste de WAY100635 $(10 \mathrm{nmol} / 0.5 \mu \mathrm{L})$ ou veículo $(0.5 \mu \mathrm{L})$, e cinco minutos depois recebram também administrações intra-hipocampais de NPA $\left(10^{-4} \mathrm{nmol} / 0.5 \mu \mathrm{L}\right)$ ou veículo $(0.5 \mu \mathrm{L})$. Os dados representam a média+EPM. * indica $\mathrm{p}<0.05$, em comparação ao grupo controle. 
DISCUSSÃO 


\section{DISCUSSÃO}

O presente estudo demonstrou que a administração intra-hipocampo dorsal de NPA, um inibidor seletivo da nNOS, induz efeito do tipo antidepressivo em animais submetidos ao teste do nado forçado e que o pré-tratamento com um inibidor seletivo de receptores $5 \mathrm{HT}_{1 \mathrm{~A}}$, WAY100635, bloqueou esse efeito, da mesma maneira que bloqueou o efeito antidepressivo induzido pela fluoxetina. Portanto, os resultados sugerem que o efeito do NPA envolve mudanças na neurotransmissão serotoninérgica local e subseqüente ativação de receptores $5-\mathrm{HT}_{1 \mathrm{~A}}$.

O teste do nado forçado é um teste com uma ampla utilização e alta preditividade de efeito antidepressivo (Willner, 1990). Este teste é baseado na observação de que roedores expostos a uma situação de nado forçado apresentam um comportamento orientado por alguns minutos e, em seguida, assumem uma postura de imobilidade (Porsolt et al., 1977; Porsolt et al., 1978; Cryan et al., 2002). O tempo que o animal assume essa postura no segundo dia de teste, um dia após a primeira exposição, é diminuído pelo tratamento com uma grande variedade de fármacos (Willner, 1984; 1990). Apesar de ser possível distinguir nitidamente drogas antidepressivas de drogas antipsicóticas e ansiolíticas em animais submetidos ao teste do nado forçado (Porsolt et al., 1977), psicoestimulantes podem induzir efeito falso positivo, diminuindo o tempo de imobilidade por estimular a atividade locomotora do animal. Uma vez que as administrações realizadas nos protocolos experimentais deste trabalho foram realizadas logo após o pré-teste, isto é, 24 horas antes do teste quando é feita a mensuração do tempo de imobilidade, efeitos psicoestimulantes induzidos pelos tratamentos realizados são muito pouco prováveis.

Nossos resultados demonstram que a administração de NPA no hipocampo dorsal de ratos induz a um efeito do tipo antidepressivo. Este resultado corrobora dados oriundos de estudos anteriores que demonstraram que a inibição da NOS pela administração sistêmica de 7-NI, um inibidor preferencial da nNOS, é capaz de reduzir o tempo de imobilidade em animais submetidos 
ao teste do nado forçado (Joca e Guimarães, 2006). No entanto, além da nNOS, a iNOS também parece regular a produção de NO que ocorre após exposição a situações de estresse, principalmente de estresse crônico, uma vez que a administração intra-hipocampal de um inibidor preferencial da iNOS, a aminoguanidina, também induz um efeito do tipo antidepressivo em animais submetidos ao modelo do estresse crônico variado (Wang et al., 2008).

Portanto, no presente trabalho utilizamos um inibidor mais seletivo para nNOS, o NPA (o Ki do NPLA para nNOS, iNOS e eNOS é $57,1,8 \times 10^{5}$ e $8500 \mathrm{nM}$, respectivamente Zhang et al., 1997), e possibilitar a investigação de que se os efeitos observados por Joca e Guimarães (2006) seriam realmente devidos à inibição da nNOS. Além disso, dados do nosso laboratório demonstraram que a administração de um inibidor seletivo para iNOS, o 1400W, em dose necessária para inibir a mesma proporção de iNOS que o NPA inibe nas doses utilizadas nesse estudo, não promoveu efeitos significativos em animais submetidos ao teste do nado forçado (Sales et al., 2011). Portanto, em conjunto, esses dados sugerem que a inibição da nNOS imediatamente após o estresse seria a responsável pelo efeito tipoantidepressivo observado em ratos com a administração de NPA.

O efeito do tipo antidepressivo induzido pela inibição da NOS também já foi demonstrado em outros modelos animais utilizados para estudo de comportamentos relacionados à depressão, como o desamparo aprendido (Joca et al., 2008), o CUMS (Mutlu et al., 2009) e o estresse de restrição agudo e crônico (Sevgi et al., 2006). Portanto, nossos resultados suportam essa idéia de que o hipocampo, especialmente sua porção dorsal, seria uma área importante para os efeitos do tipo antidepressivo observados com a administração sistêmica dos inibidores da NOS.

Isso poderia ocorrer porque os inibidores da NOS impediriam o aumento de NO induzido pelo estresse que acontece no hipocampo durante esses eventos. De fato, diversos tipos de estresse podem levar ao aumento de expressão da nNOS no hipocampo, como o teste 
do nado forçado (Keser et al., 2011), choques nas patas (Wegener et al., 2010) e CUMS (Zhou et al., 2007). Harvey e cols. demonstraram, em ratos, que a exposição repetida a situações de estresse inescapável leva a aumento da atividade da NOS no hipocampode ratos (Harvey et al., 2004) e a níveis aumentados de espécies reativas de nitrogênio $\left(\mathrm{NO}_{\mathrm{X}}\right)$ nesta estrutura (Harvey et al., 2005).

Os mecanismos envolvidos nos efeitos comportamentais induzidos pelo aumento de NO no hipocampo ainda não estão muito bem esclarecidos. Evidências apontam para um possível envolvimento da neurotransmissão serotoninérgica, uma vez o NO endógeno parece diminuir os níveis de serotonina no hipocampo (Wegener et al., 2000), enquanto a administração de Larginina, o precursor do NO, leva a uma atenuação dos efeitos do tipo antidepressivo induzidos pela sertralina, um ISRS, em camundongos submetidos ao teste do nado forçado (Inan et al., 2004). Além disso, a inibição da síntese de serotonina pela administração de p-clorofenilalanina (PCPA, um inibidor da triptofano hidroxilase) é capaz de bloquear os efeitos do tipo antidepressivo induzidos pelos inibidores da NOS, indicando que estes efeitos sejam dependentes dos níveis serotonina endógena (Harkin et al., 2003). Ainda nesse sentido, foi demonstrado que a administração de doses subefetivas de inibidores da NOS potencializa os efeitos do tipo antidepressivo em animais submetidos ao teste do nado forçado induzidos pela administração de drogas antidepressivas serotoninérgicas (Harkin et al., 2004; Gigliucci et al., 2010) e que a administração concomitante de metergolina, um antagonista não seletivo dos receptores serotoninérgicos, atenua os efeitos do tipo antidepressivo induzidos por inibidor da NOS em animais submetidos ao teste do nado forçado. Tais evidências, portanto, sugerem que a inibição da nNOS promoveria aumento dos níveis de serotonina, o que seria responsável pelo efeito tipoantidepressivo induzido pelos inibidores da NOS.

Nossos resultados corroboram essa hipótese, pois foi observado que: (1) A facilitação da neurotransmissão serotoninérgica local através da administração de fluoxetina foi capaz de 
causar efeitos do tipo antidepressivo em ratos submetidos ao teste do nado forçado (experimento 02); (2) que a inibição da síntese de NO induziu efeito semelhante à fluoxetina (experimento 01 ); (3) e que ambos os efeitos foram prevenidos pelo pré-tratamento com antagonista de receptor serotoninérgico do tipo 1A (experimentos 04 e 05). Assim, usando a mesma dose de WAY100635 que foi capaz de bloquear os efeitos da fluoxetina, nós mostramos que o efeito do tipo antidepressivo induzido pela administração de NPA também foi bloqueado, sugerindo, portanto, que os efeitos do tipo antidepressivo induzidos pela inibição da nNOS envolveriam desinibição da neurotransmissão serotoninérgica, com conseqüente aumento dos níveis locais de serotonina e ativação de receptores $5-\mathrm{HT}_{1 \mathrm{~A}}$

Diversas evidências apontam para a possibilidade de que o NO possa interferir na neurotransmissão serotoninérgica. Primeiro, estudos de imunohistoquímica indicam que há colocalização da NOS e de serotonina em projeções dos núcleos dorsal (DRN) e mediano (MRN) da rafe e outros núcleos encefálicos (Johnson e Ma, 1993; Dun et al., 1994; Wotherspoon et al., 1994; Maqbool et al., 1995; Wang et al., 1995; Leger et al., 1998). Há neurônios positivos para imunomarcação para NOS e/ou para NADPH-d em muitas das estruturas que recebem fibras oriundas dos núcleos da rafe, e, portanto, recebem inervação serotoninérgica, como a amídala (Ellison et al., 1987; Mizukawa et al., 1988; Leigh et al., 1990; Sims e Williams, 1990; Pitkanen e Amaral, 1991; Brady et al., 1992; Vincent e Kimura, 1992), a substância cinzenta periaquedutal (PAG - periaqueductal grey matter; Leigh et al., 1990; Vincent e Kimura, 1992) e a formação hipocampal (Valtschanoff et al., 1993; Vincent e Kimura, 1992). Uma vez que o NO é uma molécula que age muitas vezes como um mensageiro retrógrado, a presença de neurônios que produzem NO nas estruturas que recebem aferências dos núcleos serotoninérgicos da rafe pode indicar a possibilidade da interação entre os dois sistemas.

Também é relatado que o NO poderia agir diretamente na molécula da serotonina inativando-a por nitrosilação (Fossier et al., 1999). De fato, vários estudos apontam para a 
possibilidade do envolvimento da nitrosilação de monoaminas em transtornos psiquiátricos (Delabreteche et al., 1994; d'Ischia e Costantini, 1995; Blanchard et al., 1997). A inativação da serotonina poderia levar a uma diminuição da neurotransmissão serotoninérgica local e assim contribuir para as conseqüências comportamentais do estresse, que aumenta os níveis de NO.

Há também a possibilidade de interações do NO com outros elementos da via serotoninérgica como, por exemplo, com a triptofano hidroxilase, onde essa interação promoveria inibição da enzima e diminuição dos níveis de serotonina (Kuhn e Arthur, 1996; Kuhn e Arthur, 1997). Isso poderia explicar estudos que apontam para a possibilidade de o NO causar a depleção ou a diminuição da liberação de serotonina em determinadas células (Linden e El-Fakahany, 2002; Iuras et al., 2005) e que a facilitação da liberação de NO no hipocampo pode causar uma diminuição da liberação da serotonina ou uma diminuição nas concentrações locais de serotonina (Segieth, 2001; Smith e Whitton, 2000).

O envolvimento da neurotransmissão serotoninérgica do hipocampo dorsal, por meio da ativação de receptores $5-\mathrm{HT}_{1 \mathrm{~A}}$, na modulação de comportamentos relacionados à neurobiologia da depressão já tem sido discutido há algum tempo (Blier et al., 1987; Chalmers et al,. 1994; Flugge, 1995; Chaput et al., 1991; Invernizzi et al., 1994; Stahl, 1994; Kreiss e Lucki 1995; Hayakawa et al., 1994). A hipótese de Deakin e Graeff (1991) aponta o hipocampo como sendo uma das estruturas principais na mediação da adaptação ao estresse frente a eventos aversivos/estressantes uma vez que estes se tornem persistentes; e esse mecanismo seria justamente mediado pela ativação dos receptores $5 \mathrm{HT}_{1 \mathrm{~A}}$ que funcionariam inibindo a formação de memórias aversivas ou causando uma desconexão entre o evento aversivo e as conseqüências afetivas do estresse ao qual o indivíduo foi submetido. Isso favoreceria a sobrevivência do indivíduo aumentando sua capacidade de adaptação a situações estressantes (Graeff et al., 1996; Joca et al., 2003a).

Corroborando os dados acima, utilizando um modelo animal preditivo para efeitos do tipo antidepressivo, foi demonstrado que a administração de zimelidina, um SSRI, ou de agonista dos 
receptores $5 \mathrm{HT}_{1 \mathrm{~A}}$ no hipocampo dorsal após a exposição ao estresse foi capaz de prevenir o comportamento de desamparo em ratos, efeitos bloqueados pelo pré-tratamento com WAY100635, uma antagonista de receptores $5 \mathrm{HT}_{1 \mathrm{~A}}$ (Joca et al., 2003a; Joca et al., 2006).

Klenenhagen et al. (2006) demonstraram que camundongos KO para os receptores $5 \mathrm{HT}_{1 \mathrm{~A}}$ expostos a um modelo de condicionamento aversivo (modelo do medo condicionado ao contexto) expressam o comportamento de congelamento de maneira similar aos camundongos do tipo selvagem. Porém, quando expostos a um meio ambíguo, misturando pistas contextuais condicionadas com pistas novas, os camundongos nkock out não apresentam diminuição no comportamento de congelamento como os animais selvagens apresentam, indicando uma generalização inapropriada para o comportamento de medo parecida com a que ocorre com pacientes que sofrem de transtorno de pânico ou transtorno de estresse pós-traumático (Klenenhagen et al., 2006). Este comportamento pode resultar de um viés no processamento de estímulos aversivos, onde os animais $\mathrm{KO}$ para $5 \mathrm{HT}_{1 \mathrm{~A}}$ fariam uma associação mais forte entre o contexto e o estímulo aversivo durante o treinamento. Considerando o que já foi dito a respeito do papel do hipocampo e da importância dos receptores $5 \mathrm{HT}_{1 \mathrm{~A}}$ hipocampais no sistema de adaptação a situações de estresse, os resultados ajudam a sustentar a teoria de Deakin e Graeff, mostrando que os receptores $5 \mathrm{HT}_{1 \mathrm{~A}}$ seriam importantes para diminuir o impacto afetivo de situações estressantes no indivíduo e que sua ausência causaria um viés que favoreceria associações aversivas.

Uma das formas pelas quais os receptores $5 \mathrm{HT}_{1 \mathrm{~A}}$ no hipocampo poderiam exercer este função seria pela inibição da formação de memórias aversivas. Carli e cols. mostraram que a ativação de $5 \mathrm{HT}_{1 \mathrm{~A}}$ no hipocampo leva a déficits no aprendizado e memória em ratos submetidos ao teste do labirinto aquático de Morris (Carli et al., 1992; 1995). Corroborando isso, é sabido que a ativação de $5 \mathrm{HT}_{1 \mathrm{~A}}$ inibe a formação de LTP (long term potentiation; Sakai e Tanaka, 1993; 
Kojima et al., 2003; Tachibana et al., 2004) e a facilitação nitrérgica favorece a formação de LTP (Arancio et al., 1996a; Arancio et al., 1996b) no hipocampo de ratos.

Outra possibilidade seria da participação desses receptores na modulação dos mecanismos de plasticidade neuronal no hipocampo dorsal. Agonistas $5 \mathrm{HT}_{1 \mathrm{~A}}$ aumentam (Santarelli et al., 2003; Huang e Herbert, 2005) bem como antagonistas 5 $\mathrm{HT}_{1 \mathrm{~A}}$ diminuem a proliferação celular no giro denteado do hipocampo (Radley e Jacobs, 2002) e a expressão de BDNF (Ivy et al., 2003). Além disso, a sobrevivência de células no hipocampo é aumentada por administração de agonistas $5 \mathrm{HT}_{1 \mathrm{~A}}$, um efeito bloqueado por administração de WAY100635 (Fricker et al., 2005). Estes efeitos de proliferação celular no hipocampo são considerados importantes para o efeito das drogas antidepressivas (Radley e Jacobs, 2002; Santarelli et al., 2003) e também no funcionamento normal do sistema de enfrentamento e adaptação frente a situações aversivas, denotando a importância da ativação desse sistema local, mediado pelos receptores $5 \mathrm{HT}_{1 \mathrm{~A}}$, em relação aos mecanismos neuroplásticos presentes no hipocampo.

Isso poderia explicar os efeitos plásticos similares induzidos pelo tratamento com inibidores da NOS. Há evidências, por exemplo, de que a inibição da NOS promove não somente aumento dos níveis de serotonina no giro denteado do hipocampo, como também aumento na expressão de PSA-NCAM (molécula de adesão de células neurais polisialilada) e CREB fosforilado (pCREB - a forma ativada do CREB, Park et al., 2004), aumento na expressão de BDNF (Canossa et al., 2002) e aumento na neurogênese (Kim et al., 2006; Arora et al., 2007; Luo et al., 2007; Hu et al., 2008). A proteína CREB é um fator de transcrição que pode regular a transcrição de vários genes envolvidos com efeitos tróficos incluindo a neurogênese e a plasticidade neuronal (para revisões com CREB e depressão ver Nair e Vaidya, 2006; Gass e Riva, 2007); e a PSA-NCAM é uma molécula de adesão celular neural, que parece ser importante em processos de migração celular, crescimento axonal e plasticidade sináptica (Seki e Arai, 1993), além de regular a sobrevivência, migração e 
diferenciação de células progenitoras no SNC de animais adultos (Battista e Rutishauser, 2010; Gascon et al., 2007; Burgess et al., 2008). É possível que os efeitos comportamentais induzidos por inibidores da NOS poderiam envolver a ocorrência de processos neuroplásticos locais, os quais são importantes para a função hipocampal.

Finalmente, é importante relatar que a ativação de receptores $5 \mathrm{HT}_{1 \mathrm{~A}}$ hipocampais regula negativamente a liberação de glutamato (Dijk et al. 1995; Matsuyama et al. 1996) de NO e cGMP (Strosznajder et al., 1996), sugerindo mais uma vez a interação mútua entre os dois sistemas no hipocampo modulando o comportamento sob situações aversivas. Além disso, a administração de milnacipran, um inibidor da recaptação de serotonina e noradrenalina, induz à diminuição nos níveis de $\mathrm{NO}_{\mathrm{X}}$ no córtex e no hipocampo e também ao aumento dos níveis de BDNF nessas estruturas (Ikenouchi-Sugita et al., 2009), indicando que o aumento da disponibilidade de serotonina no local e conseqüente aumento da ativação dos receptores $5 \mathrm{HT}_{1 \mathrm{~A}}$ levaria não só a uma diminuição do NO local, que em altas concentrações pode se tornar neurotóxico, como desencadearia alterações plásticas locais, podendo favorecer a neuroproteção local. Dessa forma, parece que a via não ocorre apenas no sentido de inibição do sistema serotoninérgico pelo NO, mas também no sentido de inibição do sistema nitrérgico pela serotonina e ativação dos receptores $5 \mathrm{HT}_{1 \mathrm{~A}}$. O quanto um ou outro sentido dessa via de regulação na formação hipocampal é mais ou menos ativo durante a adaptação a situações aversivas, e particularmente, durante o processe de adaptação frente a situações de estresse crônico, não é possível saber com os dados que dispomos.

Assim, os resultados aqui apresentados indicam que a administração intra hipocampo dorsal de ambos, NPA e fluoxetina, induz a efeitos do tipo antidepressivo, diminuindo o tempo de imobilidade dos animais submetidos ao teste do nado forçado, e o pré-tratamento com WAY100635 foi capaz de bloquear estes efeitos, mostrando que esses são, ambos, dependentes da ativação dos receptores $5 \mathrm{HT}_{1 \mathrm{~A}}$ nessa estrutura encefálica. 
CONCLUSÕES 


\section{CONCLUSÕES}

- A diminuição da formação de NO ou o aumento da disponibilidade de serotonina no hipocampo dorsal induz efeitos do tipo antidepressivo em ratos submetidos ao teste do nado forçado.

- O efeito da inibição da síntese de NO é dependente de serotonina e da ativação de receptores do tipo $5 \mathrm{HT}_{1 \mathrm{~A}}$. 
REFERÊNCIAS BIBLIOGRÁFICAS 


\section{REFERÊNCIAS BIBLIOGRÁFICAS}

Abel EL, Bilitzke PJ (A possible alarm substance in the forced swimming test. Physiol Behav 48:233-239.1990).

Adachi M, Abe M, Sasaki T, Kato H, Kasahara J, Araki T (Role of inducible or neuronal nitric oxide synthase in neurogenesis of the dentate gyrus in aged mice. Metab Brain Dis 25:419-424.2010).

Arancio O, Kiebler M, Lee CJ, Lev-Ram V, Tsien RY, Kandel ER, Hawkins RD (Nitric oxide acts directly in the presynaptic neuron to produce long-term potentiation in cultured hippocampal neurons. Cell 87:1025-1035.1996a).

Arancio O, Lev-Ram V, Tsien RY, Kandel ER, Hawkins RD (Nitric oxide acts as a retrograde messenger during long-term potentiation in cultured hippocampal neurons. J Physiol Paris 90:321-322.1996b).

Arora DK, Cosgrave AS, Howard MR, Bubb V, Quinn JP, Thippeswamy T (Evidence of postnatal neurogenesis in dorsal root ganglion: role of nitric oxide and neuronal restrictive silencer transcription factor. J Mol Neurosci 32:97-107.2007).

Baldwin DS, Birtwistle J (An atlas of depression. The Parthenon Publishing Group.106p, London.2002).

Battista D, Rutishauser U (Removal of polysialic acid triggers dispersion of subventricularly derived neuroblasts into surrounding CNS tissues. J Neurosci 30:3995-4003.2010).

Bhagwagar Z, Rabiner EA, Sargent PA, Grasby PM, Cowen PJ (Persistent reduction in brain serotonin $1 \mathrm{~A}$ receptor binding in recovered depressed men measured by positron emission tomography with [11C]WAY-100635. Mol Psychiatry 9:386-392.2004).

Blanchard B, Dendane M, Gallard JF, Houee-Levin C, Karim A, Payen D, Launay JM, Ducrocq C (Oxidation, nitrosation, and nitration of serotonin by nitric oxide-derived nitrogen oxides: biological implications in the rat vascular system. Nitric Oxide 1:442-452.1997). 
Blier P, de Montigny C, Chaput Y (Modifications of the serotonin system by antidepressant treatments: implications for the therapeutic response in major depression. J Clin Psychopharmacol 7:24S-35S.1987).

Booij L, Van der Does AJ, Riedel WJ (Monoamine depletion in psychiatric and healthy populations: review. Mol Psychiatry 8:951-973.2003).

Brady DR, Carey RG, Mufson EJ (Reduced nicotinamide adenine dinucleotide phosphate-diaphorase (NADPH-d) profiles in the amygdala of human and New World monkey (Saimiri sciureus). Brain Res 577:236-248.1992).

Bremner JD (Does stress damage the brain? Biol Psychiatry 45:797-805.1999).

Burgess A, Wainwright SR, Shihabuddin LS, Rutishauser U, Seki T, Aubert I (Polysialic acid regulates the clustering, migration, and neuronal differentiation of progenitor cells in the adult hippocampus. Dev Neurobiol 68:1580-1590.2008).

Calabrese V, Mancuso C, Calvani M, Rizzarelli E, Butterfield DA, Stella AM (Nitric oxide in the central nervous system: neuroprotection versus neurotoxicity. Nat Rev Neurosci 8:766-775.2007).

Campbell S, Macqueen G (The role of the hippocampus in the pathophysiology of major depression. J Psychiatry Neurosci 29:417-426.2004).

Canossa M, Giordano E, Cappello S, Guarnieri C, Ferri S (Nitric oxide downregulates brain-derived neurotrophic factor secretion in cultured hippocampal neurons. Proc Natl Acad Sci U S A 99:3282-3287.2002).

Carli M, Lazarova M, Tatarczynska E, Samanin R (Stimulation of 5-HT1A receptors in the dorsal hippocampus impairs acquisition and performance of a spatial task in a water maze. Brain Res 595:50-56.1992).

Carli M, Luschi R, Garofalo P, Samanin R (8-OH-DPAT impairs spatial but not visual learning in a water maze by stimulating 5-HT1A receptors in the hippocampus. Behav Brain Res 67:67-74.1995).

Carli M, Tatarczynska E, Cervo L, Samanin R (Stimulation of hippocampal 5HT1A receptors causes amnesia and anxiolytic-like but not antidepressantlike effects in the rat. Eur J Pharmacol 234:215-221.1993). 
Caspi A, Sugden K, Moffitt TE, Taylor A, Craig IW, Harrington H, McClay J, Mill J, Martin J, Braithwaite A, Poulton R (Influence of life stress on depression: moderation by a polymorphism in the 5-HTT gene. Science 301:386-389.2003).

Castren E (Is mood chemistry? Nat Rev Neurosci 6:241-246.2005).

Chalmers DT, Kwak SP, Mansour A, Akil H, Watson SJ (Corticosteroids regulate brain hippocampal 5-HT1A receptor mRNA expression. J Neurosci 13:914-923.1993).

Chaput Y, de Montigny C, Blier P (Presynaptic and postsynaptic modifications of the serotonin system by long-term administration of antidepressant treatments. An in vivo electrophysiologic study in the rat. Neuropsychopharmacology 5:219-229.1991).

Cryan JF, Page ME, Lucki I (Noradrenergic lesions differentially alter the antidepressant-like effects of reboxetine in a modified forced swim test. Eur J Pharmacol 436:197-205.2002).

Czeh B, Lucassen PJ (What causes the hippocampal volume decrease in depression? Are neurogenesis, glial changes and apoptosis implicated? Eur Arch Psychiatry Clin Neurosci 257:250-260.2007).

d'Ischia M, Costantini C (Nitric oxide-induced nitration of catecholamine neurotransmitters: a key to neuronal degeneration? Bioorg Med Chem 3:923927.1995).

de Kloet ER (Stress in the brain. Eur J Pharmacol 405:187-198.2000).

Deakin JF (Depression and 5HT. Int Clin Psychopharmacol 6 Suppl 3:23-28; discussion 29-31.1991).

Delabreteche ML, Servy C, Lenfant M, Ducrocq C (Nitration of Catecholamines with Nitrogen-Oxides in Mild Conditions - a Hypothesis for the Reactivity of No in Physiological Systems. Tetrahedron Lett 35:7231-7232.1994). 
Delgado PL (Monoamine depletion studies: implications for antidepressant discontinuation syndrome. J Clin Psychiatry 67 Suppl 4:22-26.2006).

Dijk SN, Francis PT, Stratmann GC, Bowen DM (NMDA-induced glutamate and aspartate release from rat cortical pyramidal neurones: evidence for modulation by a 5-HT1A antagonist. Br J Pharmacol 115:1169-1174.1995).

Drevets WC, Frank E, Price JC, Kupfer DJ, Greer PJ, Mathis C (Serotonin type1A receptor imaging in depression. Nucl Med Biol 27:499-507.2000).

Duman RS, Monteggia LM (A neurotrophic model for stress-related mood disorders. Biol Psychiatry 59:1116-1127.2006).

Dun NJ, Dun SL, Forstermann U (Nitric-Oxide Synthase Immunoreactivity in Rat Pontine Medullary Neurons. Neuroscience 59:429-445.1994).

Ellison DW, Kowall NW, Martin JB (Subset of neurons characterized by the presence of NADPH-diaphorase in human substantia innominata. J Comp Neurol 260:233-245.1987).

Eriksson TM, Delagrange P, Spedding M, Popoli M, Mathe AA, Ogren SO, Svenningsson P (Emotional memory impairments in a genetic rat model of depression: involvement of 5-HT/MEK/Arc signaling in restoration. Mol Psychiatry.2011).

Flugge G (Dynamics of central nervous 5-HT1A-receptors under psychosocial stress. J Neurosci 15:7132-7140.1995).

Flugge G, Kramer M, Rensing S, Fuchs E (5 $\mathrm{HT}_{1 \mathrm{~A}}$-receptors and behaviour under chronic stress: selective counteraction by testosterone. Eur J Neurosci 10:2685-2693.1998).

Fossier P, Blanchard B, Ducrocq C, Leprince C, Tauc L, Baux G (Nitric oxide transforms serotonin into an inactive form and this affects neuromodulation. Neuroscience 93:597-603.1999).

Fricker AD, Rios C, Devi LA, Gomes I (Serotonin receptor activation leads to neurite outgrowth and neuronal survival. Brain Res Mol Brain Res 138:228235.2005). 
Garthwaite J, Charles SL, Chess-Williams R (Endothelium-derived relaxing factor release on activation of NMDA receptors suggests role as intercellular messenger in the brain. Nature 336:385-388.1988).

Gascon E, Vutskits L, Jenny B, Durbec P, Kiss JZ (PSA-NCAM in postnatally generated immature neurons of the olfactory bulb: a crucial role in regulating p75 expression and cell survival. Development 134:1181-1190.2007).

Gass P, Riva MA (CREB, neurogenesis and depression. Bioessays 29:957961.2007).

Gerlach JL, McEwen BS (Rat brain binds adrenal steroid hormone: radioautography of hippocampus with corticosterone. Science 175:1133-1136.1972).

Gigliucci V, Buckley KN, Nunan J, O'Shea K, Harkin A (A role for serotonin in the antidepressant activity of NG-Nitro-L-arginine, in the rat forced swimming test. Pharmacol Biochem Behav 94:524-533.2010).

Giovacchini G, Lang L, Ma Y, Herscovitch P, Eckelman WC, Carson RE (Differential effects of paroxetine on raphe and cortical 5-HT1A binding: a PET study in monkeys. Neuroimage 28:238-248.2005).

Gould E, McEwen BS, Tanapat P, Galea LA, Fuchs E (Neurogenesis in the dentate gyrus of the adult tree shrew is regulated by psychosocial stress and NMDA receptor activation. J Neurosci 17:2492-2498.1997).

Gould E, Tanapat P (Stress and hippocampal neurogenesis. Biol Psychiatry 46:1472-1479.1999).

Graeff FG, Guimaraes FS, De Andrade TG, Deakin JF (Role of 5-HT in stress, anxiety, and depression. Pharmacol Biochem Behav 54:129-141.1996).

Guimaraes FS, Beijamini V, Moreira FA, Aguiar DC, de Lucca AC (Role of nitric oxide in brain regions related to defensive reactions. Neurosci Biobehav Rev 29:1313-1322.2005).

Harkin A, Connor TJ, Burns MP, Kelly JP (Nitric oxide synthase inhibitors augment the effects of serotonin re-uptake inhibitors in the forced swimming test. Eur Neuropsychopharmacol 14:274-281.2004). 
Harkin A, Connor TJ, Walsh M, St John N, Kelly JP (Serotonergic mediation of the antidepressant-like effects of nitric oxide synthase inhibitors. Neuropharmacology 44:616-623.2003).

Harvey BH, Bothma T, Nel A, Wegener G, Stein DJ (Involvement of the NMDA receptor, NO-cyclic GMP and nuclear factor K-beta in an animal model of repeated trauma. Hum Psychopharmacol 20:367-373.2005).

Harvey BH, Duvenhage I, Viljoen F, Scheepers N, Malan SF, Wegener G, Brink $\mathrm{CB}$, Petzer JP (Role of monoamine oxidase, nitric oxide synthase and regional brain monoamines in the antidepressant-like effects of methylene blue and selected structural analogues. Biochem Pharmacol 80:15801591.2010).

Harvey BH, Oosthuizen F, Brand L, Wegener G, Stein DJ (Stress-restress evokes sustained iNOS activity and altered GABA levels and NMDA receptors in rat hippocampus. Psychopharmacology (Berl) 175:494502.2004).

Hayakawa H, Shimizu M, Nishida A, Motohashi N, Yamawaki S (Increase in serotonin $1 \mathrm{~A}$ receptors in the dentate gyrus as revealed by autoradiographic analysis following repeated electroconvulsive shock but not imipramine treatment. Neuropsychobiology 30:53-56.1994).

Heiberg IL, Wegener G, Rosenberg R (Reduction of cGMP and nitric oxide has antidepressant-like effects in the forced swimming test in rats. Behav Brain Res 134:479-484.2002).

Hirvonen J, Karlsson H, Kajander J, Lepola A, Markkula J, Rasi-Hakala H, Nagren K, Salminen JK, Hietala J (Decreased brain serotonin 5-HT1A receptor availability in medication-naive patients with major depressive disorder: an in-vivo imaging study using PET and [carbonyl-11C]WAY100635. Int J Neuropsychopharmacol 11:465-476.2008).

Holmans P, Weissman MM, Zubenko GS, Scheftner WA, Crowe RR, Depaulo JR, Jr., Knowles JA, Zubenko WN, Murphy-Eberenz K, Marta DH, Boutelle S, McInnis MG, Adams P, Gladis M, Steele J, Miller EB, Potash JB, Mackinnon DF, Levinson DF (Genetics of recurrent early-onset major depression (GenRED): final genome scan report. Am J Psychiatry 164:248258.2007). 
Hu M, Sun YJ, Zhou QG, Chen L, Hu Y, Luo CX, Wu JY, Xu JS, Li LX, Zhu DY (Negative regulation of neurogenesis and spatial memory by NR2Bcontaining NMDA receptors. J Neurochem 106:1900-1913.2008).

Huang GJ, Herbert $\mathbf{J}$ (Stimulation of neurogenesis in the hippocampus of the adult rat by fluoxetine requires rhythmic change in corticosterone. Biol Psychiatry 59:619-624.2006).

Ikenouchi-Sugita A, Toyohira Y, Yoshimura R, Ueno S, Tsutsui M, Nakamura J, Yanagihara N (Opposite effects of milnacipran, a serotonin norepinephrine reuptake inhibitor, on the levels of nitric oxide and brain-derived neurotrophic factor in mouse brain cortex. Naunyn Schmiedebergs Arch Pharmacol 380:479-486.2009).

Inan SY, Yalcin I, Aksu F (Dual effects of nitric oxide in the mouse forced swimming test: possible contribution of nitric oxide-mediated serotonin release and potassium channel modulation. Pharmacol Biochem Behav 77:457-464.2004).

Invernizzi R, Bramante $\mathrm{M}$, Samanin $\mathrm{R}$ (Chronic treatment with citalopram facilitates the effect of a challenge dose on cortical serotonin output: role of presynaptic 5-HT1A receptors. Eur J Pharmacol 260:243-246.1994).

Ishihara K, Amano T, Hayakawa H, Yamawaki S, Sasa M (Enhancement of serotonin(1A) receptor function following repeated electroconvulsive shock in young rat hippocampal neurons in vitro. Int $\mathrm{J}$ Neuropsychopharmacol 2:101-104.1999).

Iuras A, Telles MM, Bertoncini CR, Ko GM, de Andrade IS, Silveira VL, Ribeiro EB (Central administration of a nitric oxide precursor abolishes both the hypothalamic serotonin release and the hypophagia induced by interleukin-1beta in obese Zucker rats. Regul Pept 124:145-150.2005).

Ivy AS, Rodriguez FG, Garcia C, Chen MJ, Russo-Neustadt AA (Noradrenergic and serotonergic blockade inhibits BDNF mRNA activation following exercise and antidepressant. Pharmacol Biochem Behav 75:81-88.2003).

Jefferys D, Funder $\mathrm{J}$ (Nitric oxide modulates retention of immobility in the forced swimming test in rats. Eur J Pharmacol 295:131-135.1996). 
Joca S, Stanquini L, Ferreira F, Guimaraes F (Chronic, but not acute, inhibition of nitric oxide (NO) synthesis prevents learned helplessness development in rats. International Journal of Neuropsychopharmacology 11:122-122.2008).

Joca SR, Ferreira FR, Guimaraes FS (Modulation of stress consequences by hippocampal monoaminergic, glutamatergic and nitrergic neurotransmitter systems. Stress 10:227-249.2007).

Joca SR, Guimaraes FS (Inhibition of neuronal nitric oxide synthase in the rat hippocampus induces antidepressant-like effects. Psychopharmacology (Berl) 185:298-305.2006).

Joca SR, Padovan CM, Guimaraes FS (Activation of post-synaptic 5-HT(1A) receptors in the dorsal hippocampus prevents learned helplessness development. Brain Res 978:177-184.2003a).

Joca SR, Padovan CM, Guimaraes FS ([Stress, depression and the hippocampus]. Rev Bras Psiquiatr 25 Suppl 2:46-51.2003b).

Joca SR, Zanelati T, Guimaraes FS (Post-stress facilitation of serotonergic, but not noradrenergic, neurotransmission in the dorsal hippocampus prevents learned helplessness development in rats. Brain Res 1087:67-74.2006).

Joels M (Functional actions of corticosteroids in the hippocampus. Eur $\mathrm{J}$ Pharmacol 583:312-321.2008).

Johnson MD, Ma PM (Localization of Nadph Diaphorase Activity in Monoaminergic Neurons of the Rat-Brain. J Comp Neurol 332:391406.1993).

Karten YJ, Nair SM, van Essen L, Sibug R, Joels M (Long-term exposure to high corticosterone levels attenuates serotonin responses in rat hippocampal CA1 neurons. Proc Natl Acad Sci U S A 96:13456-13461.1999).

Katz MM, Bowden CL, Frazer A (Rethinking depression and the actions of antidepressants: uncovering the links between the neural and behavioral elements. J Affect Disord 120:16-23.2010). 
Keks NA, Burrows GD, Copolov DL, Newton R, Paoletti N, Schweitzer I, Tiller $\mathrm{J}$ (Beyond the evidence: is there a place for antidepressant combinations in the pharmacotherapy of depression? Med J Aust 186:142-144.2007).

Kendler KS, Kessler RC, Walters EE, MacLean C, Neale MC, Heath AC, Eaves LJ (Stressful life events, genetic liability, and onset of an episode of major depression in women. Am J Psychiatry 152:833-842.1995).

Kennett GA, Dickinson SL, Curzon G (Central serotonergic responses and behavioural adaptation to repeated immobilisation: the effect of the corticosterone synthesis inhibitor metyrapone. Eur J Pharmacol 119:143152.1985a).

Kennett GA, Dickinson SL, Curzon G (Enhancement of some 5-HT-dependent behavioural responses following repeated immobilization in rats. Brain Res 330:253-263.1985b).

Kennett GA, Marcou M, Dourish CT, Curzon G (Single administration of 5HT1A agonists decreases 5-HT1A presynaptic, but not postsynaptic receptormediated responses: relationship to antidepressant-like action. Eur J Pharmacol 138:53-60.1987).

Keser A, Balkan B, Gozen O, Kanit L, Pogun S (Hippocampal neuronal nitric oxide synthase (nNOS) is regulated by nicotine and stress in female but not in male rats. Brain Res 1368:134-142).

Kessler RC, Angermeyer M, Anthony JC, R DEG, Demyttenaere K, Gasquet I, G DEG, Gluzman S, Gureje O, Haro JM, Kawakami N, Karam A, Levinson D, Medina Mora ME, Oakley Browne MA, Posada-Villa J, Stein DJ, Adley Tsang CH, Aguilar-Gaxiola S, Alonso J, Lee S, Heeringa S, Pennell BE, Berglund P, Gruber MJ, Petukhova M, Chatterji S, Ustun TB (Lifetime prevalence and age-of-onset distributions of mental disorders in the World Health Organization's World Mental Health Survey Initiative. World Psychiatry 6:168-176.2007).

Khovryakov AV, Podrezova EP, Kruglyakov PP, Shikhanov NP, Balykova MN, Semibratova NV, Sosunov AA, McKhann G, 2nd, Airapetyants MG (Involvement of the NO synthase system in stress-mediated brain reactions. Neurosci Behav Physiol 40:333-337). 
Kim SH, Won SJ, Mao XO, Ledent C, Jin K, Greenberg DA (Role for neuronal nitric-oxide synthase in cannabinoid-induced neurogenesis. J Pharmacol Exp Ther 319:150-154.2006).

Klemenhagen KC, Gordon JA, David DJ, Hen R, Gross CT (Increased fear response to contextual cues in mice lacking the 5-HT1A receptor. Neuropsychopharmacology 31:101-111.2006).

Klimek V, Papp M (The effect of MK-801 and imipramine on beta-adrenergic and 5-HT2 receptors in the chronic mild stress model of depression in rats. Pol J Pharmacol 46:67-69.1994).

Knowles RG, Palacios M, Palmer RM, Moncada S (Formation of nitric oxide from L-arginine in the central nervous system: a transduction mechanism for stimulation of the soluble guanylate cyclase. Proc Natl Acad Sci U S A 86:5159-5162.1989).

Kojima T, Matsumoto M, Togashi H, Tachibana K, Kemmotsu O, Yoshioka M (Fluvoxamine suppresses the long-term potentiation in the hippocampal CA1 field of anesthetized rats: an effect mediated via 5-HT1A receptors. Brain Res 959:165-168.2003).

Kreiss DS, Lucki I (Effects of acute and repeated administration of antidepressant drugs on extracellular levels of 5-hydroxytryptamine measured in vivo. J Pharmacol Exp Ther 274:866-876.1995).

Kuhn DM, Arthur R, Jr. (Molecular mechanism of the inactivation of tryptophan hydroxylase by nitric oxide: attack on critical sulfhydryls that spare the enzyme iron center. J Neurosci 17:7245-7251.1997).

Kuhn DM, Arthur RE, Jr. (Inactivation of brain tryptophan hydroxylase by nitric oxide. J Neurochem 67:1072-1077.1996).

Lapin IP, Oxenkrug GF (Intensification of the central serotoninergic processes as a possible determinant of the thymoleptic effect. Lancet 1:132-136.1969).

Layer RT, Popik P, Olds T, Skolnick P (Antidepressant-like actions of the polyamine site NMDA antagonist, eliprodil (SL-82.0715). Pharmacol Biochem Behav 52:621-627.1995). 
Lee J, Duan W, Mattson MP (Evidence that brain-derived neurotrophic factor is required for basal neurogenesis and mediates, in part, the enhancement of neurogenesis by dietary restriction in the hippocampus of adult mice. $\mathrm{J}$ Neurochem 82:1367-1375.2002).

Leger L, Charnay Y, Burlet S, Gay N, Schaad N, Bouras C, Cespuglio R (Comparative distribution of nitric oxide synthase- and serotonin-containing neurons in the raphe nuclei of four mammalian species. Histochem Cell Biol 110:517-525.1998).

Leigh PN, Connick JH, Stone TW (Distribution of NADPH-diaphorase positive cells in the rat brain. Comp Biochem Physiol C 97:259-264.1990).

Lerer B, Gelfin Y, Gorfine M, Allolio B, Lesch KP, Newman ME (5-HT1A receptor function in normal subjects on clinical doses of fluoxetine: blunted temperature and hormone responses to ipsapirone challenge. Neuropsychopharmacology 20:628-639.1999).

Li N, Lee B, Liu RJ, Banasr M, Dwyer JM, Iwata M, Li XY, Aghajanian G, Duman RS (mTOR-dependent synapse formation underlies the rapid antidepressant effects of NMDA antagonists. Science 329:959-964).

Li N, Liu RJ, Dwyer JM, Banasr M, Lee B, Son H, Li XY, Aghajanian G, Duman RS (Glutamate N-methyl-D-aspartate receptor antagonists rapidly reverse behavioral and synaptic deficits caused by chronic stress exposure. Biol Psychiatry 69:754-761).

Linden DR, El-Fakahany EE (Microglial derived nitric oxide decreases serotonin content in rat basophilic leukemia (RBL-2H3) cells. Eur J Pharmacol 436:53-56.2002).

Lopez-Figueroa AL, Norton CS, Lopez-Figueroa MO, Armellini-Dodel D, Burke S, Akil H, Lopez JF, Watson SJ (Serotonin 5-HT1A, 5-HT1B, and 5HT2A receptor mRNA expression in subjects with major depression, bipolar disorder, and schizophrenia. Biol Psychiatry 55:225-233.2004).

Lopez JF, Chalmers DT, Little KY, Watson SJ (A.E. Bennett Research Award. Regulation of serotonin1A, glucocorticoid, and mineralocorticoid receptor in rat and human hippocampus: implications for the neurobiology of depression. Biol Psychiatry 43:547-573.1998). 
Lucassen PJ, Muller MB, Holsboer F, Bauer J, Holtrop A, Wouda J, Hoogendijk WJ, De Kloet ER, Swaab DF (Hippocampal apoptosis in major depression is a minor event and absent from subareas at risk for glucocorticoid overexposure. Am J Pathol 158:453-468.2001a).

Lucassen PJ, Vollmann-Honsdorf GK, Gleisberg M, Czeh B, De Kloet ER, Fuchs E (Chronic psychosocial stress differentially affects apoptosis in hippocampal subregions and cortex of the adult tree shrew. Eur J Neurosci $14: 161-166.2001 b)$.

Lundberg J, Borg J, Halldin C, Farde L (A PET study on regional coexpression of 5-HT1A receptors and 5-HTT in the human brain. Psychopharmacology (Berl) 195:425-433.2007).

Luo CX, Zhu XJ, Zhou QG, Wang B, Wang W, Cai HH, Sun YJ, Hu M, Jiang J, Hua Y, Han X, Zhu DY (Reduced neuronal nitric oxide synthase is involved in ischemia-induced hippocampal neurogenesis by up-regulating inducible nitric oxide synthase expression. J Neurochem 103:1872-1882.2007).

Maj J, Rogoz Z, Skuza G, Sowinska H (The effect of CGP 37849 and CGP 39551, competitive NMDA receptor antagonists, in the forced swimming test. Pol J Pharmacol Pharm 44:337-346.1992a).

Maj J, Rogoz Z, Skuza G, Sowinska H (Effects of MK-801 and antidepressant drugs in the forced swimming test in rats. Eur Neuropsychopharmacol 2:3741.1992b).

Malberg JE, Duman RS (Cell proliferation in adult hippocampus is decreased by inescapable stress: reversal by fluoxetine treatment. Neuropsychopharmacology 28:1562-1571.2003).

Maqbool A, Batten TFC, Mcwilliam PN (Colocalization of Neurotransmitter Immunoreactivities in Putative Nitric-Oxide Synthesizing Neurons of the Cat Brain-Stem. J Chem Neuroanat 8:191-206.1995).

Matsuyama S, Nei K, Tanaka C (Regulation of glutamate release via NMDA and 5-HT1A receptors in guinea pig dentate gyrus. Brain Res 728:175180.1996). 
McBlane JW, Handley SL (Effects of two stressors on behaviour in the elevated X-maze: preliminary investigation of their interaction with 8-OH-DPAT. Psychopharmacology (Berl) 116:173-182.1994).

McEwen BS (Protection and damage from acute and chronic stress: allostasis and allostatic overload and relevance to the pathophysiology of psychiatric disorders. Ann N Y Acad Sci 1032:1-7.2004).

McEwen BS (Physiology and neurobiology of stress and adaptation: central role of the brain. Physiol Rev 87:873-904.2007).

McEwen BS, Weiss JM, Schwartz LS (Selective retention of corticosterone by limbic structures in rat brain. Nature 220:911-912.1968).

McKittrick CR, Magarinos AM, Blanchard DC, Blanchard RJ, McEwen BS, Sakai RR (Chronic social stress reduces dendritic arbors in CA3 of hippocampus and decreases binding to serotonin transporter sites. Synapse $36: 85-94.2000)$.

McLeod TM, Lopez-Figueroa AL, Lopez-Figueroa MO (Nitric oxide, stress, and depression. Psychopharmacol Bull 35:24-41.2001).

Meloni D, Gambarana C, De Montis MG, Dal Pra P, Taddei I, Tagliamonte A (Dizocilpine antagonizes the effect of chronic imipramine on learned helplessness in rats. Pharmacol Biochem Behav 46:423-426.1993).

Mizukawa K, McGeer PL, Vincent SR, McGeer EG (Ultrastructure of reduced nicotinamide adenine dinucleotide phosphate (NADPH) diaphorase-positive neurons in the cat cerebral cortex, amygdala and caudate nucleus. Brain Res 452:286-292.1988).

Murray CJ, Lopez AD (Global mortality, disability, and the contribution of risk factors: Global Burden of Disease Study. Lancet 349:1436-1442.1997).

Mutlu O, Ulak G, Laugeray A, Belzung C (Effects of neuronal and inducible NOS inhibitor 1-[2-(trifluoromethyl) phenyl] imidazole (TRIM) in unpredictable chronic mild stress procedure in mice. Pharmacol Biochem Behav 92:82-87.2009). 
Nair A, Vaidya VA (Cyclic AMP response element binding protein and brainderived neurotrophic factor: molecules that modulate our mood? J Biosci 31:423-434.2006).

Naylor GJ, Smith AH, Connelly P (A controlled trial of methylene blue in severe depressive illness. Biol Psychiatry 22:657-659.1987).

Nestler EJ (Antidepressant treatments in the 21st century. Biol Psychiatry 44:526-533.1998).

Nestler EJ, Barrot M, DiLeone RJ, Eisch AJ, Gold SJ, Monteggia LM (Neurobiology of depression. Neuron 34:13-25.2002).

Netto SM, Guimaraes FS (Role of hippocampal 5-HT1A receptors on elevated plus maze exploration after a single restraint experience. Behav Brain Res 77:215-218.1996).

Nimgaonkar VL, Goodwin GM, Davies CL, Green AR (Down-regulation of beta-adrenoceptors in rat cortex by repeated administration of desipramine, electroconvulsive shock and clenbuterol requires 5-HT neurones but not 5HT. Neuropharmacology 24:279-283.1985).

Olesen J, Baker MG, Freund T, di Luca M, Mendlewicz J, Ragan I, Westphal M (Consensus document on European brain research. J Neurol Neurosurg Psychiatry 77 Suppl 1:11-49.2006).

Oliveira RM, Guimaraes FS, Deakin JF (Expression of neuronal nitric oxide synthase in the hippocampal formation in affective disorders. Braz J Med Biol Res 41:333-341.2008).

Organização Mundial da Saúde (Classificação internacional estatística das doenças e problemas de saúde relacionados 10a versão Atualizada - CID - 10 em: http://apps.who.int/classifications/apps/icd/icd10online/ versão 2007. Acesso em: 21 de maio de 2011).

Padovan CM, Guimaraes FS (Antidepressant-like effects of NMDA-receptor antagonist injected into the dorsal hippocampus of rats. Pharmacol Biochem Behav 77:15-19.2004). 
Papp M, Moryl E (New evidence for the antidepressant activity of MK-801, a non-competitive antagonist of NMDA receptors. Pol J Pharmacol 45:549553.1993).

Papp M, Moryl E (Antidepressant activity of non-competitive and competitive NMDA receptor antagonists in a chronic mild stress model of depression. Eur J Pharmacol 263:1-7.1994).

Park C, Cho K, Ryu JH, Shin KS, Kim J, Ahn H, Huh Y (7-Nitroindazole upregulates phosphorylated cAMP response element binding protein, polysialylated-neural cell adhesion molecule and tryptophan hydroxylase expression in the adult rat hippocampus. Brain Res 1008:120-125.2004).

Paul IA, Trullas R, Skolnick P, Nowak G (Down-regulation of cortical betaadrenoceptors by chronic treatment with functional NMDA antagonists. Psychopharmacology (Berl) 106:285-287.1992).

Pineyro G, Blier P (Autoregulation of serotonin neurons: role in antidepressant drug action. Pharmacol Rev 51:533-591.1999).

Pitkanen A, Amaral DG (Distribution of reduced nicotinamide adenine dinucleotide phosphate diaphorase (NADPH-d) cells and fibers in the monkey amygdaloid complex. J Comp Neurol 313:326-348.1991).

Pitsikas N, Rigamonti AE, Cella SG, Sakellaridis N, Muller EE (The nitric oxide donor molsidomine antagonizes age-related memory deficits in the rat. Neurobiol Aging 26:259-264.2005a).

Pitsikas N, Tsitsirigou S, Zisopoulou S, Sakellaridis N (The 5-HT1A receptor and recognition memory. Possible modulation of its behavioral effects by the nitrergic system. Behav Brain Res 159:287-293.2005b).

Pittenger C, Duman RS (Stress, depression, and neuroplasticity: a convergence of mechanisms. Neuropsychopharmacology 33:88-109.2008).

Porsolt RD, Anton G, Blavet N, Jalfre M (Behavioural despair in rats: a new model sensitive to antidepressant treatments. Eur J Pharmacol 47:379391.1978). 
Porsolt RD, Bertin A, Jalfre M (Behavioral despair in mice: a primary screening test for antidepressants. Arch Int Pharmacodyn Ther 229:327-336.1977).

Post RM (Transduction of psychosocial stress into the neurobiology of recurrent affective disorder. Am J Psychiatry 149:999-1010.1992).

Prast H, Philippu A (Nitric oxide as modulator of neuronal function. Prog Neurobiol 64:51-68.2001).

Przegalinski E, Tatarczynska E, Deren-Wesolek A, Chojnacka-Wojcik E (Antidepressant-like effects of a partial agonist at strychnine-insensitive glycine receptors and a competitive NMDA receptor antagonist. Neuropharmacology 36:31-37.1997).

Radley JJ, Jacobs BL (5-HT1A receptor antagonist administration decreases cell proliferation in the dentate gyrus. Brain Res 955:264-267.2002).

Sackeim HA, Manji HK, Perera TD, Santarelli L, Kornack D, Kempermann G, Eisch A (Environmental and pharmacological regulation of hippocampal neurogenesis. Biol Psychiat 53:3S-3S.2003).

Sakai N, Tanaka C (Inhibitory modulation of long-term potentiation via the 5HT1A receptor in slices of the rat hippocampal dentate gyrus. Brain Res 613:326-330.1993).

Sanacora G, Zarate CA, Krystal JH, Manji HK (Targeting the glutamatergic system to develop novel, improved therapeutics for mood disorders. Nat Rev Drug Discov 7:426-437.2008).

Santarelli L, Saxe M, Gross C, Surget A, Battaglia F, Dulawa S, Weisstaub N, Lee J, Duman R, Arancio O, Belzung C, Hen R (Requirement of hippocampal neurogenesis for the behavioral effects of antidepressants. Science 301:805-809.2003).

Savitz J, Lucki I, Drevets WC (5-HT(1A) receptor function in major depressive disorder. Prog Neurobiol 88:17-31.2009). 
Schildkraut JJ (The catecholamine hypothesis of affective disorders: a review of supporting evidence. Am J Psychiatry 122:509-522.1965).

Segieth J, Pearce B, Fowler L, Whitton PS (Regulatory role of nitric oxide over hippocampal 5-HT release in vivo. Naunyn Schmiedebergs Arch Pharmacol 363:302-306.2001).

Seidenbecher T, Laxmi TR, Stork O, Pape HC (Amygdalar and hippocampal theta rhythm synchronization during fear memory retrieval. Science 301:846$850.2003)$.

Seki T, Arai Y (Distribution and possible roles of the highly polysialylated neural cell adhesion molecule (NCAM-H) in the developing and adult central nervous system. Neurosci Res 17:265-290.1993).

Sevgi S, Ozek M, Eroglu L (L-NAME prevents anxiety-like and depression-like behavior in rats exposed to restraint stress. Methods Find Exp Clin Pharmacol 28:95-99.2006).

Sheline YI, Mittler BL, Mintun MA (The hippocampus and depression. Eur Psychiatry 17 Suppl 3:300-305.2002).

Shumake J, Edwards E, Gonzalez-Lima F (Dissociation of septo-hippocampal metabolism in the congenitally helpless rat. Neuroscience 114:373377.2002).

Sims KS, Williams RS (The human amygdaloid complex: a cytologic and histochemical atlas using Nissl, myelin, acetylcholinesterase and nicotinamide adenine dinucleotide phosphate diaphorase staining. Neuroscience 36:449-472.1990).

Smith JC, Whitton PS (Nitric oxide modulates N-methyl-D-aspartate-evoked serotonin release in the raphe nuclei and frontal cortex of the freely moving rat. Neurosci Lett 291:5-8.2000).

Southwick SM, Vythilingam M, Charney DS (The psychobiology of depression and resilience to stress: implications for prevention and treatment. Annu Rev Clin Psychol 1:255-291.2005). 
Stahl SM, Hauger RL, Rausch JL, Fleishaker JC, Hubbell-Alberts E (Downregulation of serotonin receptor subtypes by nortriptyline and adinazolam in major depressive disorder: neuroendocrine and platelet markers. Clin Neuropharmacol 16 Suppl 3:S19-31.1993).

Strosznajder J, Chalimoniuk M, Samochocki M (Activation of serotonergic 5HT1A receptor reduces $\mathrm{Ca}(2+)$ - and glutamatergic receptor-evoked arachidonic acid and No/cGMP release in adult hippocampus. Neurochem Int 28:439-444.1996).

Sullivan PF, Neale MC, Kendler KS (Genetic epidemiology of major depression: review and meta-analysis. Am J Psychiatry 157:1552-1562.2000).

Suzuki E, Yagi G, Nakaki T, Kanba S, Asai M (Elevated plasma nitrate levels in depressive states. J Affect Disord 63:221-224.2001).

Szabo ST, Blier P (Effects of chronic antidepressant drug administration and electroconvulsive shock on locus coeruleus electrophysiologic activity. Biol Psychiatry 50:644-646.2001).

Tachibana K, Matsumoto M, Togashi H, Kojima T, Morimoto Y, Kemmotsu O, Yoshioka M (Milnacipran, a serotonin and noradrenaline reuptake inhibitor, suppresses long-term potentiation in the rat hippocampal CA1 field via 5HT1A receptors and alpha 1-adrenoceptors. Neurosci Lett 357:91-94.2004).

Tanapat P, Hastings NB, Reeves AJ, Gould E (Estrogen stimulates a transient increase in the number of new neurons in the dentate gyrus of the adult female rat. J Neurosci 19:5792-5801.1999).

Tanapat P, Hastings NB, Rydel TA, Galea LA, Gould E (Exposure to fox odor inhibits cell proliferation in the hippocampus of adult rats via an adrenal hormone-dependent mechanism. J Comp Neurol 437:496-504.2001).

Trullas R, Skolnick P (Functional antagonists at the NMDA receptor complex exhibit antidepressant actions. Eur J Pharmacol 185:1-10.1990).

Valtschanoff JG, Weinberg RJ, Kharazia VN, Nakane M, Schmidt HH (Neurons in rat hippocampus that synthesize nitric oxide. J Comp Neurol 331:111121.1993). 
van Riel E, Meijer OC, Steenbergen PJ, Joels M (Chronic unpredictable stress causes attenuation of serotonin responses in cornu ammonis 1 pyramidal neurons. Neuroscience 120:649-658.2003).

van Riel E, van Gemert NG, Meijer OC, Joels M (Effect of early life stress on serotonin responses in the hippocampus of young adult rats. Synapse 53:1119.2004).

Verge D, Daval G, Marcinkiewicz M, Patey A, el Mestikawy S, Gozlan H, Hamon M (Quantitative autoradiography of multiple 5-HT1 receptor subtypes in the brain of control or 5,7-dihydroxytryptamine-treated rats. J Neurosci 6:3474-3482.1986).

Vincent SR, Kimura H (Histochemical mapping of nitric oxide synthase in the rat brain. Neuroscience 46:755-784.1992).

Wang D, An SC, Zhang X (Prevention of chronic stress-induced depression-like behavior by inducible nitric oxide inhibitor. Neurosci Lett 433:59-64.2008).

Wang QP, Guan JL, Nakai Y (Distribution and Synaptic Relations of Nos Neurons in the Dorsal Raphe Nucleus - a Comparison to 5-Ht Neurons. Brain Research Bulletin 37:177-187.1995).

Wegener G, Harvey BH, Bonefeld B, Muller HK, Volke V, Overstreet DH, Elfving B (Increased stress-evoked nitric oxide signalling in the Flinders sensitive line (FSL) rat: a genetic animal model of depression. Int $\mathrm{J}$ Neuropsychopharmacol 13:461-473).

Wegener G, Volke V, Harvey BH, Rosenberg R (Local, but not systemic, administration of serotonergic antidepressants decreases hippocampal nitric oxide synthase activity. Brain Res 959:128-134.2003).

Wegener G, Volke V, Rosenberg $\mathrm{R}$ (Endogenous nitric oxide decreases hippocampal levels of serotonin and dopamine in vivo. Br J Pharmacol 130:575-580.2000).

Willner P (The validity of animal models of depression. Psychopharmacology (Berl) 83:1-16.1984). 
Willner P (Animal models of depression: an overview. Pharmacol Ther 45:425455.1990).

Willner P, Mitchell PJ (The validity of animal models of predisposition to depression. Behav Pharmacol 13:169-188.2002).

Wotherspoon G, Albert M, Rattray M, Priestley JV (Serotonin and NadphDiaphorase in the Dorsal Raphe Nucleus of the Adult-Rat. Neuroscience Letters 173:31-36.1994).

Yildiz F, Erden BF, Ulak G, Utkan T, Gacar N (Antidepressant-like effect of 7nitroindazole in the forced swimming test in rats. Psychopharmacology (Berl) 149:41-44.2000).

Zhang HQ, Fast W, Marletta MA, Martasek P, Silverman RB (Potent and selective inhibition of neuronal nitric oxide synthase by $\mathrm{N}$ omega-propyl-Larginine. J Med Chem 40:3869-3870.1997).

Zhou QG, Hu Y, Hua Y, Hu M, Luo CX, Han X, Zhu XJ, Wang B, Xu JS, Zhu DY (Neuronal nitric oxide synthase contributes to chronic stress-induced depression by suppressing hippocampal neurogenesis. J Neurochem 103:1843-1854.2007). 